Review Paper

\title{
Review on microfluidic device applications for fluids separation and water treatment processes
}

\author{
H. S. Santana ${ }^{1} \cdot$ J. L. Silva Jr. ${ }^{2} \cdot$ B. Aghel ${ }^{3} \cdot$ J. Ortega-Casanova ${ }^{4}$
}

Received: 31 January 2019 / Accepted: 24 January 2020 / Published online: 12 February 2020

(c) Springer Nature Switzerland AG 2020

\begin{abstract}
This review deals with a particular application of microfluidic devices such as fluids separation and water treatment. Through the different sections of the document, the reader can find not only a state of the art of specific applications related to fluids separation but also how this kind of micro-technology is being efficiently used by designing novel devices to carry out specific tasks of separation and water purification. In particular, this work has focused in three important processes: liquid-liquid separation; separation of biological samples; and water purification. After reading the document, the reader will have a clear view of how different microfluidic devices and technologies can be efficiently used in separation processes.
\end{abstract}

Keywords Microfluidic devices · Separation processes · Liquid-liquid · Biological samples · Water purification

$\begin{array}{ll}\text { Abbreviations } \\ \text { ATPS } & \text { Aqueous two-phase systems } \\ \text { A/V } & \text { Area-to-volume ratio } \\ \text { BDD } & \text { Boron-doped diamond } \\ \text { BSA } & \text { Bovine serum albumin } \\ \text { CAA } & \text { Chloroacetic acid } \\ \text { CE } & \text { Chip electrophoresis } \\ \text { CNT } & \text { Carbon nanotube } \\ \text { DEP } & \text { Dielectrophoresis } \\ \text { DNA } & \text { Deoxyribonucleic acid } \\ \text { FB } & \text { Flow-by } \\ \text { FA } & \text { Formic acid } \\ \text { FT } & \text { Flow-through } \\ \text { FTMR } & \text { Flow-through microreactor } \\ \text { GAC } & \text { Granular activated carbon } \\ \text { IDT } & \text { Interdigitated transducer } \\ \text { IE } & \text { Inter-electrode } \\ \text { IL } & \text { lonic liquids } \\ \text { IR } & \text { Immobilized reactors }\end{array}$

$\begin{array}{ll}\text { ITO } & \text { Indium-tin oxide } \\ \text { LED } & \text { Light-emitting diode } \\ \text { MD } & \text { Molecular dynamics } \\ \text { MF } & \text { Microfiltration } \\ \text { MOF } & \text { Metal-organic frameworks } \\ \text { MR } & \text { Microreactor } \\ \text { MSF } & \text { Multistage flash } \\ \text { MWCO } & \text { Molecular weight cut-off } \\ \text { NF } & \text { Nanofiltration } \\ \text { PCR } & \text { Polymerase chain reaction } \\ \text { PDMS } & \text { Polydimethylsiloxane } \\ \text { PMMA } & \text { Poly methyl methacrylate } \\ \text { PMR } & \text { Planar microreactor } \\ \text { PSTY } & \text { Photocatalytic space-time yield } \\ \text { PTFE } & \text { Polytetrafluoroethylene } \\ \text { RNA } & \text { Ribonucleic acid } \\ \text { RO } & \text { Reverse osmosis } \\ \text { SCF } & \text { Super critical fluids } \\ \text { SR } & \text { Slurry reactors }\end{array}$

J. Ortega-Casanova, jortega@uma.es; H. S. Santana, harrison.santana@gmail.com; J. L. Silva Jr. , joaolameujr@gmail.com; B. Aghel, babakaghel@gmail.com | 1 School of Chemical Engineering, University of Campinas, Campinas, SP 13083-852, Brazil. ${ }^{2}$ Federal Institute of Education, Science and Technology of South of Minas Gerais - IFSULDEMINAS, Pouso Alegre, MG 37560-260, Brazil. ${ }^{3}$ Department of Chemical Engineering, Faculty of Energy, Kermanshah University of Technology, Kermanshah, Iran. ${ }^{4}$ Andalucia Tech, Escuela de Ingenierias Industriales, University of Malaga, C/ Dr. Ortiz Ramos s/n, 29071 Málaga, Spain. 
SSAW Standing surface acoustic wave

TOC Total organic carbon

TTMSS Tris(trimethylsilyl)silane

UF Ultrafiltration

UV Ultraviolet

\section{Introduction}

Microfluidics is the science and technology of system handling low amount of fluids, using structures from tens to hundreds of micrometres [107]. Microfluidics allow obtaining great advantages from microscale in comparison with macroscopic methods. These advantages, together with many usual examples one can find in industrial processes, will be discussed in this review focused on two particular applications: fluids separation and water purification. The next three sections are dedicated to three different kinds of fluid-involved processes where separation steps or chemical treatment must be conducted.

\section{Liquid-liquid extraction}

\subsection{Introduction}

Liquid-liquid extraction or solvent extraction is an important purification or separation process in which the components of a solution, separate from the primary liquid by contacting another immiscible liquid. This process has at least three components, and they all are present in the immiscible phases. The driving force of mass transfer is the chemical differences between the two phases, which distributes the components between the two phases and the relative separation of the components [10]. This process, as a possible alternative to distillation, can be used for separation due to the low both relative volatility of the components and sensitivity to the separation heat of components.

In the selection of the extraction phase, a wide range of liquids can be used, but the following should be taken into account in their selection [33]:

1. Selectivity; 2 . Distribution coefficient; 3 . Solubility; 4. Recoverability; 5 . Density; 6 . Surface tension; and 7. Chemical activity.

This operation was successively used in chemical, oil and petrochemical processes in the separation of aromatics, aliphatic materials or hydrocarbons $[32,53]$. For many decades, the solvent extraction was used to separate biological compounds from fermentation media, isolate the antibiotics or recovery the proteins by researchers $[29,54$, 74]. Additionally, the operation has several applications in nuclear and mineral industries for the extraction of radioactive salts [110], in environmental processes for the treatment of wastewater [81] and industrial waste from the hydrometallurgy, electroplating and electrochemical industries containing heavy, toxic and non-degradable heavy metal cation $[56,88]$.

\subsection{Challenges and future}

Due to the high demand, the use of this method has increased dramatically over recent years. So, many types of research have been conducted by authors to improve mass transfer between the immiscible liquid phases by faster internal recirculation. Based on previous studies, the efficiency of extraction can be maximized by increasing the interface area and reducing the mass transfer resistance $[3,14]$. As an example, the surface area of the interface between the immiscible phases can be increased by creating smaller droplets of the dispersed phase. However, by changing the droplets size, a balance should be considered between increasing the efficiency and formation of emulsions, because smaller droplets create a balanced emulsion which makes it difficult to separate the phases [8]. The mass transfer resistance also decreases with increasing temperature as a result of reduced viscosity of the fluid. This behaviour arises from the balance of viscous forces and surface tension which against each other [30].

Development of liquid-liquid extraction processes has made progress in the production of various extractors to increase the efficiency in different industries. These extractors can be divided into the following categories: Mixer-Settlers, centrifugal extractors, and columns [18]. Although the conventional liquid-liquid extraction with high volumes of fluid has advantages, the post-separation stage requires a costly and time-consuming operation. Additionally, extraction processes use a lot of raw materials/solvents and energy to achieve chemical equilibrium state [83].

To overcome the impact of the toxic organic phase, waste materials and more control in liquid-liquid extraction devices, miniaturization were suggested by different researchers $[46,59,71]$. Microfluidic technology is one of the novel technologies most widely used in micro-scale for accurate and controlled experiments on fluids, due to low residence time and favourable conditions.

By application of these devices, many advantages, inherently linked to the operation in micro dimensions, will arise over conventional type extractors as: (i) the flow is laminar with lack of turbulence [89]; (ii) smaller space occupation on demand [102]; (iii) high surface-to-volume ratio; (iv) efficient and less energy consumption byproducts [49]; and (v) effective process control for toxic or hazardous chemicals which are difficult to handle with traditional technologies [27]. 
Moreover, extensive research is ongoing to develop microfluidic applications in many areas as biology, microbiology, pharmacy, tissue engineering, biotechnology, nanotechnology, chemical engineering, and medical engineering $[41,64]$.

Generally, these devices consist of the following parts: (1) microfluidic device; (2) pressure-driven devices, like syringes or peristaltic pumps; (3) connections system between the devices; and (4) detection tools for the analyse. Considering the specific structure, it is possible to find these devices with channel lengths below $900 \mu \mathrm{m}$, commonly in the range of $10-500 \mu \mathrm{m}$.

The first attempt to use the extraction with microfluidic was by Brody and Yager [13]. They used the mixture of water with small fluorescent dye carboxyfluorescein (CF) and fluorescent spheres ( $0.5 \mu \mathrm{m}$ diameter) in an $\mathrm{H}$-shaped microchannel. Mary et al. [61] investigated mass transfer between moving water droplets and octanol as an external phase in a rectangular microchannel which was $250 \mu \mathrm{m}$ wide and between 30 and $95 \mu \mathrm{m}$ for the height. They examined the influence of many parameters as flow rates, channel dimensions, viscosities, droplet spacing, and drop size.

Regarding the materials the microfluidic devices are made of, they are usually quartz, silicon, glass, metals, polydimethylsiloxane (PDMS) or poly methyl methacrylate (PMMA) $[24,96,107]$. However, the use of the material strongly depends on costs, compatibility of the devices with reagents and solvents, and detection techniques. The most common polymer used is PDMS because it is chemically inert and transparent, flexible and has a low cost.

The extraction of orange(II) + methyl blue into ionic liquid droplets ([EMIm][NTf2]) has been recently reviewed by Barikbin et al. [6]. Their PDMS microfluidic device has a rectangular shape with a width, height, and length of $300 \mu \mathrm{m}, 155 \mu \mathrm{m}$ and $0.45 \mathrm{~m}$, respectively. In another study described by Maruyama et al. [60], p-chlorophenol was extracted with isooctane/laccase and succinic acid buffer in a glass microchannel.

These devices can be classified into different groups based on the shape or type of junction such as $X, H, T, \Psi$, and $Y / S$ shaped $[69,72]$, Jiang et al. [38, 105]. However, the two most common shapes in microfluidic devices are $T$ and $Y-Y$.

Dessimoz et al. [22] studied the mass transfer performance and flow patterns between two immiscible liquids (deionized water and dyed toluene (or hexane)) in $\mathrm{T}$ - and Y-shaped rectangular glass microchannels. For the Y-shaped glass microfluidic devices with a guideline structure, the same study was performed by Tagawa et al. [97]. In this study hydrolysis of benzoyl chloride was selected as a model for performing organic-aqueous reactions.

\subsection{Usual applications}

The liquid-liquid extraction process using microfluidic devices is a well-explored method. Because of the importance of this subject and its applications, several articles have been published. So that, from the beginning of the twentieth century, more than 200 articles have been published applying microfluidic devices to improve the liquid-liquid extraction. Some applications of this process can be summarized as follows:

1. To prevent the thermal decomposition of materials; in which, extraction can be a good alternative to distillation or evaporation, e.g., in the Biological and Pharmaceutical industries.

2. To separate metal ions from dilute solutions, which can even compete with other chemical methods in the mineral industry.

3. In cases where the vapour pressure of the components is close to each other (volatility coefficient near 1), e.g., in separation of chemical products.

4. In processes where separation by conventional liquidliquid extraction methods are performed with difficulties by choosing a suitable and novel solvent e.g., in ionic liquids (IL) or aqueous two-phase systems (ATPS) it leads to relative separation of the material.

\subsubsection{Pharmaceutical and biological application}

With regards to versatility and efficiency of these devices, much effort has been put into the extraction of compounds from biological media. For example, they have been applied in the separations of organic molecules, cells and dyes [42, 67, 70, 93], Sun et al. [95]. In particular, Miyaguchi et al. [65] have described the liquid-liquid extraction for gas-chromatography analysis of amphetamine-type stimulants in a microchip-based in a 1-chlorobutane/alkalinized urine (complex matrix) system for forensic toxicology, see Fig. 1.

The same extraction was studied by using serpentine microchannels by Hu et al. [36] to purify membrane proteins from crude cell extract. To evaluate this method, different separation and detection methods were applied with an aqueous polyethylene glycol/detergent twophase system.

\subsubsection{Separation of metal ions}

The most important applications of liquid-liquid extraction using microfluidic devices have done in the separation of metal ions. As a practical application, these devices 


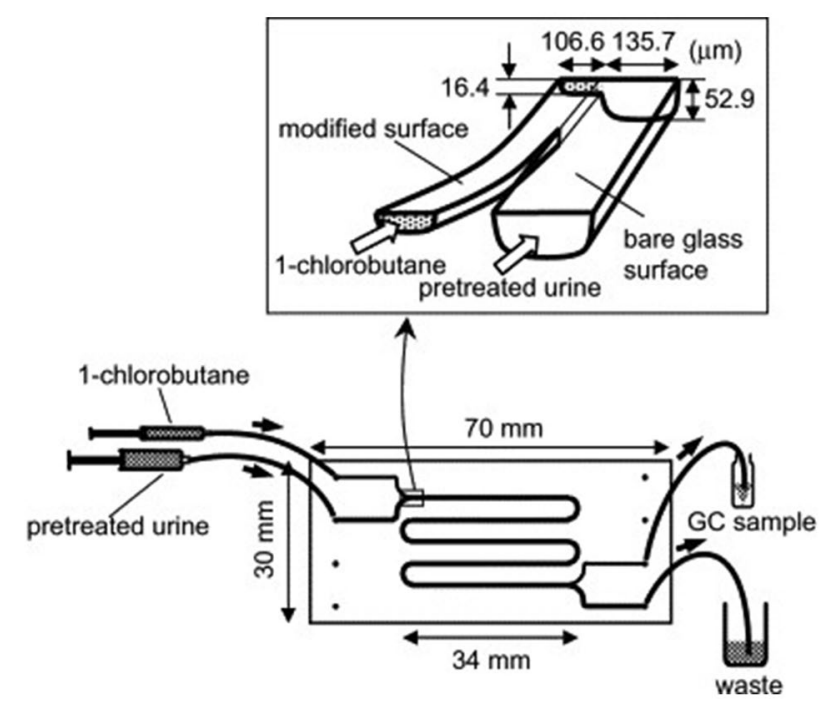

Fig. 1 Sketch of a microchip for liquid-liquid extraction. Reprinted with permission from Miyaguchi et al. [65]

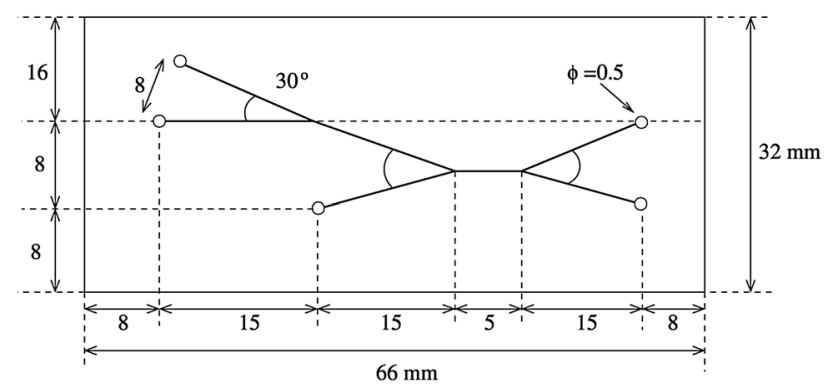

Fig. 2 Sketch and dimensions of the microdevice used in Minagawa et al. [63]. The microchannels are $100 \mu \mathrm{m}$ deep and $250 \mu \mathrm{m}$ wide. Adapted by the authors

have been applied to the extraction of cobalt, copper, nickel, iron, or rare earth metal ions [20], Jiang et al. [39, 55], Ciceri et al. [17, 108].

Kurniawan et al. [47] reported on the selectivity of the diethylamide derivative as an extraction reagent to extract $\mathrm{Pb}$ (II) ion over several other metal ions. Their results show that using a microfluidic reactor (see Fig. 2), an extraction time of around $2 \mathrm{~s}$ can be achieved. Another illustration of extraction was given by Minagawa et al. [63], who combined a wet analysis on a glass chip with $m$-xylene/2nitroso-1-naphthol chelates system to extract Co(II) ions.

\subsubsection{Separation of chemical products}

In the context of traditional liquid-liquid extraction, this process has been done using microfluidics devices by many researchers $[43,44,111]$. Up to now, different extraction systems in microchannels have been investigated. In particular, Das et al. [21] showed that to improve the liquid-liquid extraction efficiency of phenol from silicone oil to water in multiphase droplet-based microfluidic reactors (as the one shown in Fig. 3), the relative effect of flow rates of the external continuous phase to dispersed oil phase is higher than others.

The comparison of microchannels and conventional stage-wise extractors for liquid-liquid extraction using a water/succinic acid/n-butanol system was studied by Singh et al. [90]. Furthermore, they showed that maximum volumetric mass transfer coefficient and specific extraction rates could be easily achieved.

\subsubsection{Separation by novel solvent systems}

In recent years, to meet environmental sustainability goals, novel and greener solvents have been proposed. Among them, ATPS ionic liquids (IL), and supercritical fluids (SCF) can be found in extensive works on liquid-liquid extraction $[1,91,99]$.

The concept of using ATPS to separate and purify bovine serum albumin (BSA) from polyethylene glycol 4000 and ammonium sulfate in a coaxial capillary microfluidic device has been presented by Huang et al. [37] (see Fig. 4). They showed that with just three cycles to extract BSA, a recovery yield of around $70 \%$ can be achieved in just $3.6 \mathrm{~s}$.

On the other hand, Fukuyama et al. [26] studied the radical-based carbonylation reaction of alkyl halides via tributyltin hydride, or tris(trimethylsilyl)silane (TTMSS), under pressurized carbon monoxide gas in a T-shaped microfluidic system.

\section{Microdevices for separation of biological samples}

\subsection{Introduction}

Biotechnology applications are one of the most outstanding areas of Microfluidics. The capacity of scale reduction of biological systems jointly with the accomplishment of multiple experiments in a single chip is a very attractive concept, arising great interest of academic community.

This section is devoted to present different techniques and microfluidic devices to deal with separation of biological samples usually present in processes related with deoxyribonucleic acid (DNA), ribonucleic acid (RNA), acid drugs, parallel genetic analysis, blood samples, disease diagnosis or blood plasma, among others. 


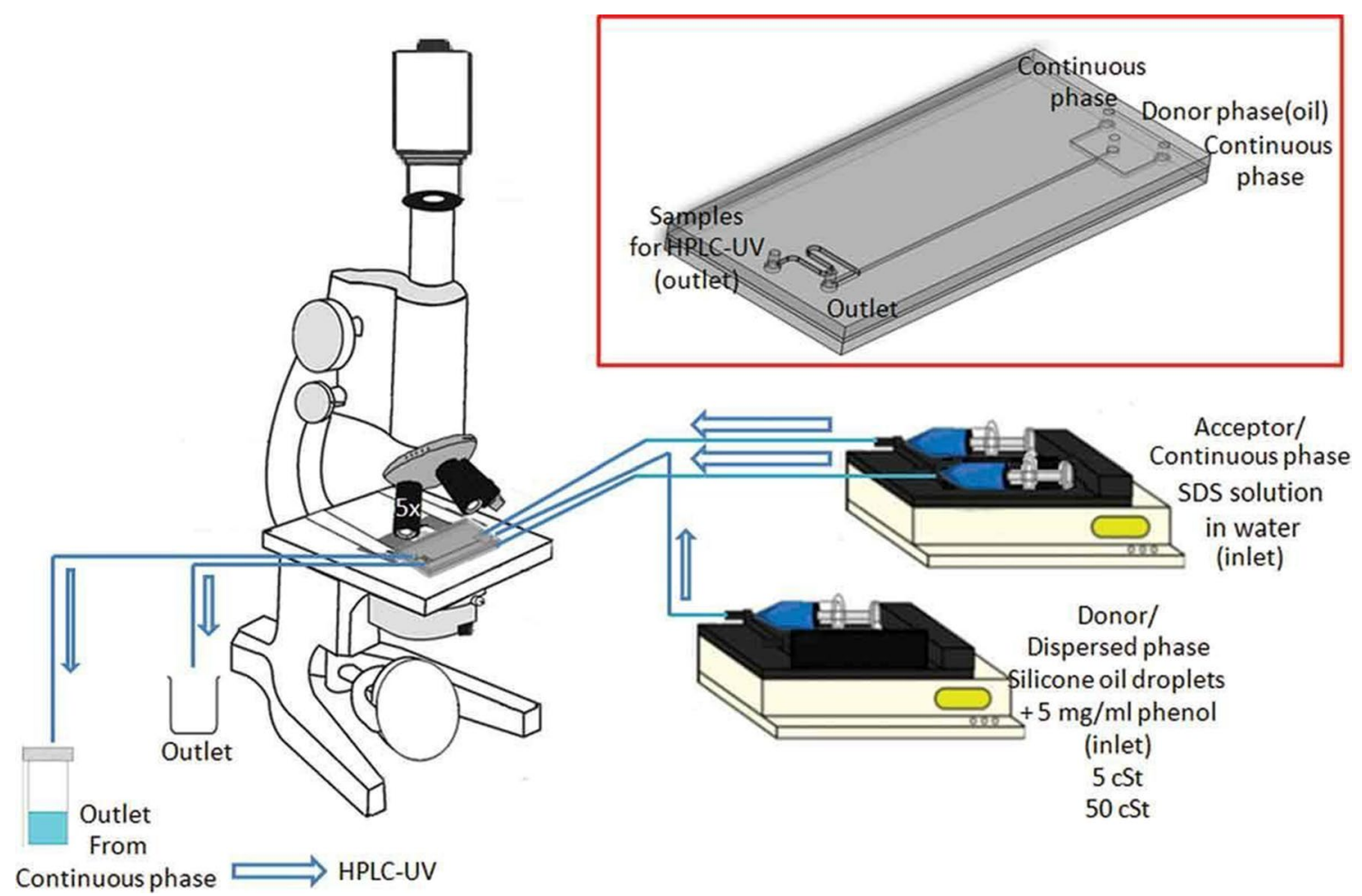

Fig. 3 Experimental set-up used in Das et al. [21]. The inset shows the microdevice made of PMMA. Reprinted with permission

\subsection{Usual applications}

Gumuscu et al. [31] developed a low cost and easy manufacturing microdevice made of glass, for ultrafast separation and purification of DNA. The new chip was capable to perform DNA fragmentation in only few minutes, while conventional approaches could take hours. The microfluidic device also presents high resolution and fragment purification, removing salts from the DNA sample. Low amounts of DNA, as used in medical diagnosis and forensic medicine, are sufficient. Figure 5 presents a description of the microfluidic chip. It consisted in three main parts: the bottom part, that includes a glass window allowing to observe the DNA fragmentation in epifluorescent inverted microscopes; the medium part, which presents slits acting as buffer reservoirs directly contacted to the buffer reservoirs in the microchip. These reservoirs are filled with buffer solution to allow contact with platinum wires; and the top part, that has orifices to align the platinum wires with the centre reservoirs. Finally, the wires are connected to an electric source.

Ramos-Payan et al. [80] studied extraction and determination of acid drugs using a microfluidic-based liquidphase microextraction device. The liquid-phase microextraction was combined with a high performance liquid chromatography procedure. The developed devices exhibited extraction efficiencies higher than $87 \%$ and
$72 \%$ for all tested acid drugs in urine and environmental samples, respectively. The microdevices consisted in two symmetric plates of polymethacrylate with inlets and outlets. The front side contained a channel with donor solution (sample). The rear side was employed as the acceptor channel. The channels were $13 \mathrm{~mm}$ long, $80 \mu \mathrm{m}$ deep and $2 \mathrm{~mm}$ wide.

A common technique used in biological separation is the electrophoresis. According to Fritsch and Krause [25], electrophoresis is a general term used to describe migration and separation of charged particles (ions) under the influence of an electric field, i.e. this technique can be used to separate charged particles based on the difference of their migration velocities.

Pan et al. [75] developed a simple integrated microdevice (Fig. 6) with multiples polymerase chain reaction (PCR) chambers and multiple separation channels based on chip electrophoresis (CE) for parallel genetics analysis. The microdevice also presented temperature control. The PCR product was introduced in the CE channels, where the electric field promoted separation and detection. According to the authors, using parallel channels allows easy determination of the exact size of the PCR products adding DNA markers and semi-quantitatively measuring of DNA sample concentration. The results suggested the potential application for qualitative DNA analysis. 

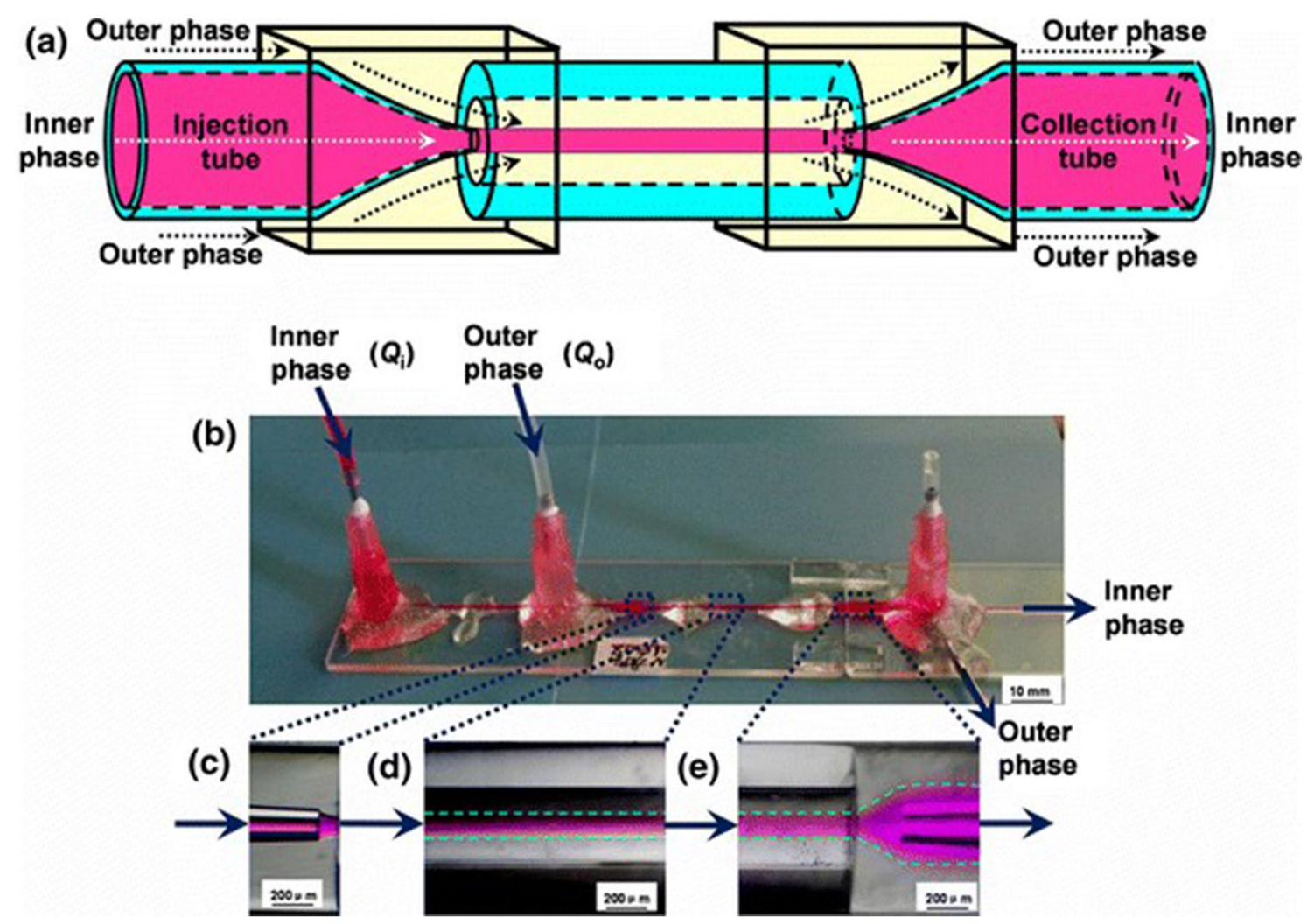

Fig. 4 a Sketch of the coaxial capillary microfluidic device. $\mathbf{b}$ Photo of the microdevice: $Q_{i}$ is the inner phase flow rate and $Q_{0}$ is the outer one. c-e represent, respectively, the injection tube, the cylin- drical glass capillary tube, and collection tube. Reprinted with permission from Huang et al. [37] (a)

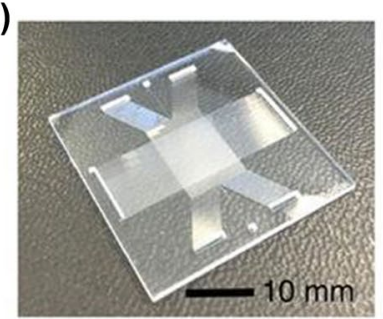

(b)

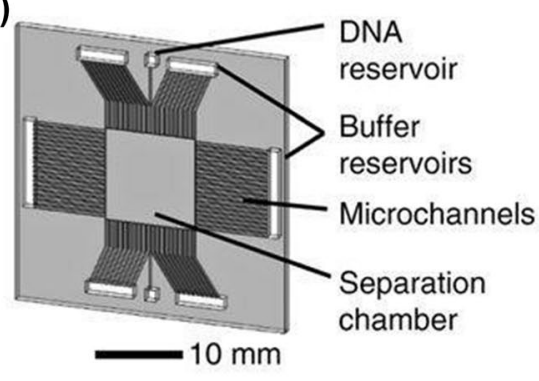

(c)

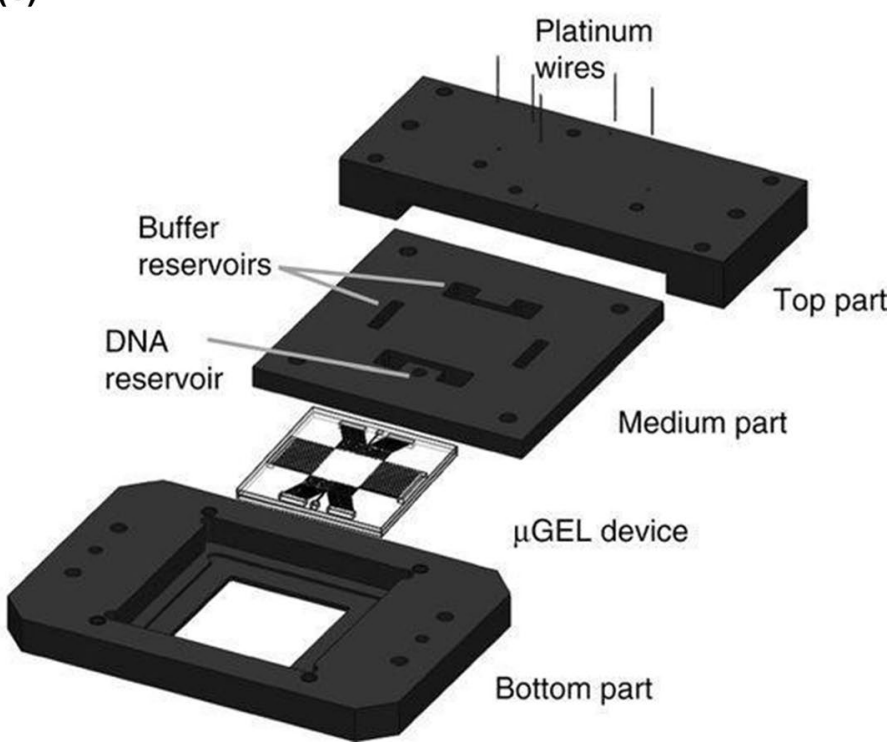

Fig. 5 Microdevice design used to separate and fragmentate DNA samples: a glass microdevice, b microchip layout (reservoirs indicated), $\mathbf{c}$ support made of Delrin and its schematics. Reprinted from [31] 

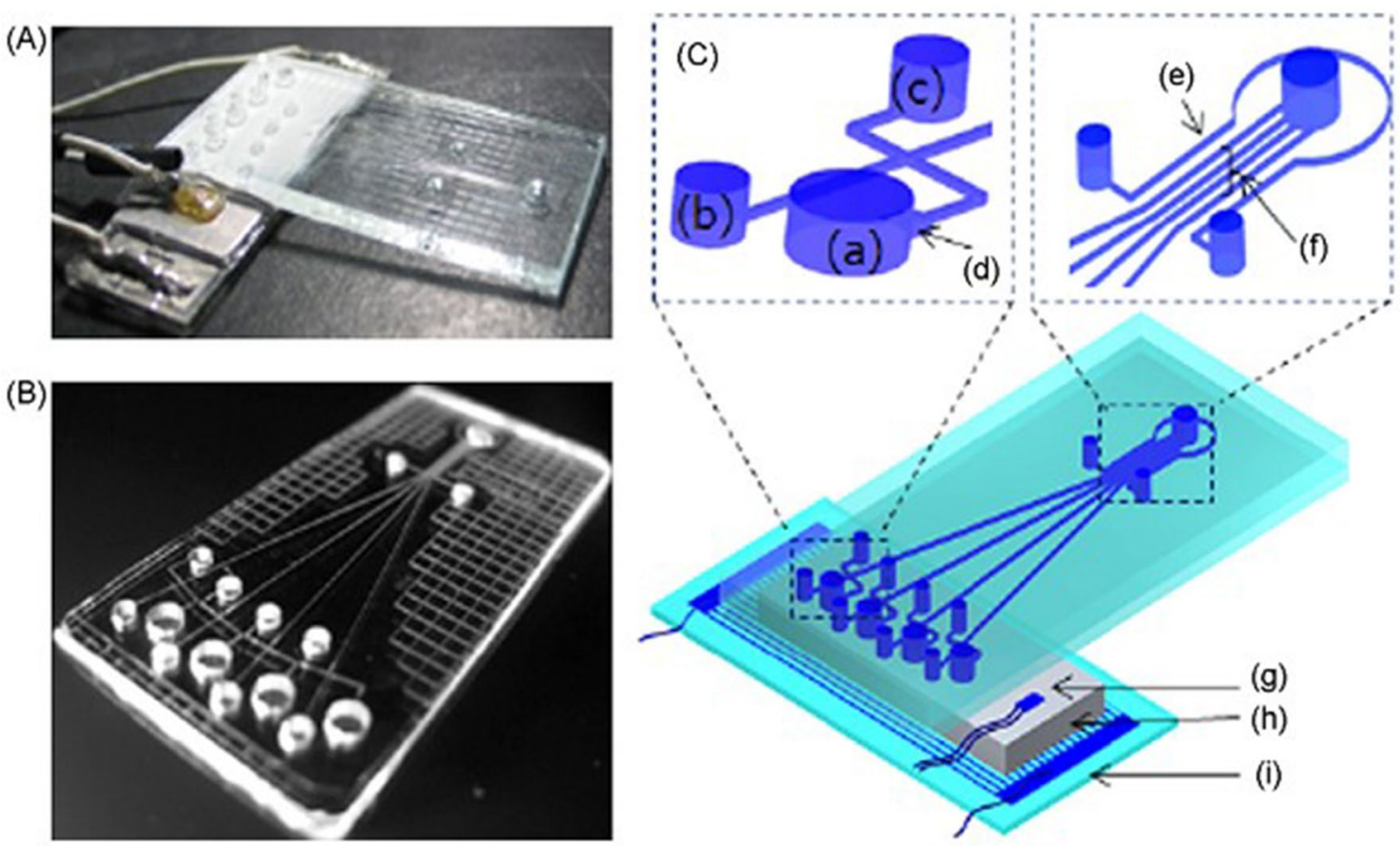

(B)

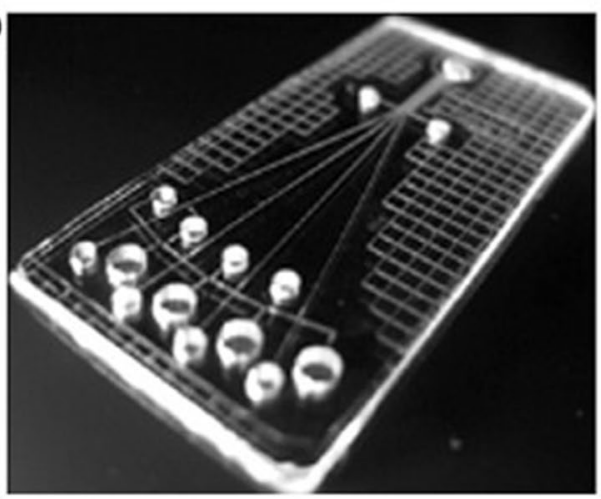

Fig. 6 Integrated microdevice with multiple PCR chambers and multiple electrophoresis-based separation channels. Reprinted with permission from Pan et al. [75]

Li and Bashir [52] using dielectrophoresis (DEP, i.e. dielectric particles motion in a non-uniform electric field) to develop a separation system for live and heat-treated L. innocua cells in water. The efficiency was $90 \%$ applying a signal of $1 \mathrm{~V}$ at $50 \mathrm{kHz}$. The authors manufactured interdigitated microelectrodes in a glass surface. The electrodes width and spacing between adjacent electrodes were $15 \mu \mathrm{m}$ (Fig. 7). Bisceglia et al. [9] proposed a microdevice for bacteria (Escherichia coli) and yeast (Candida albicans) separation from blood samples. These
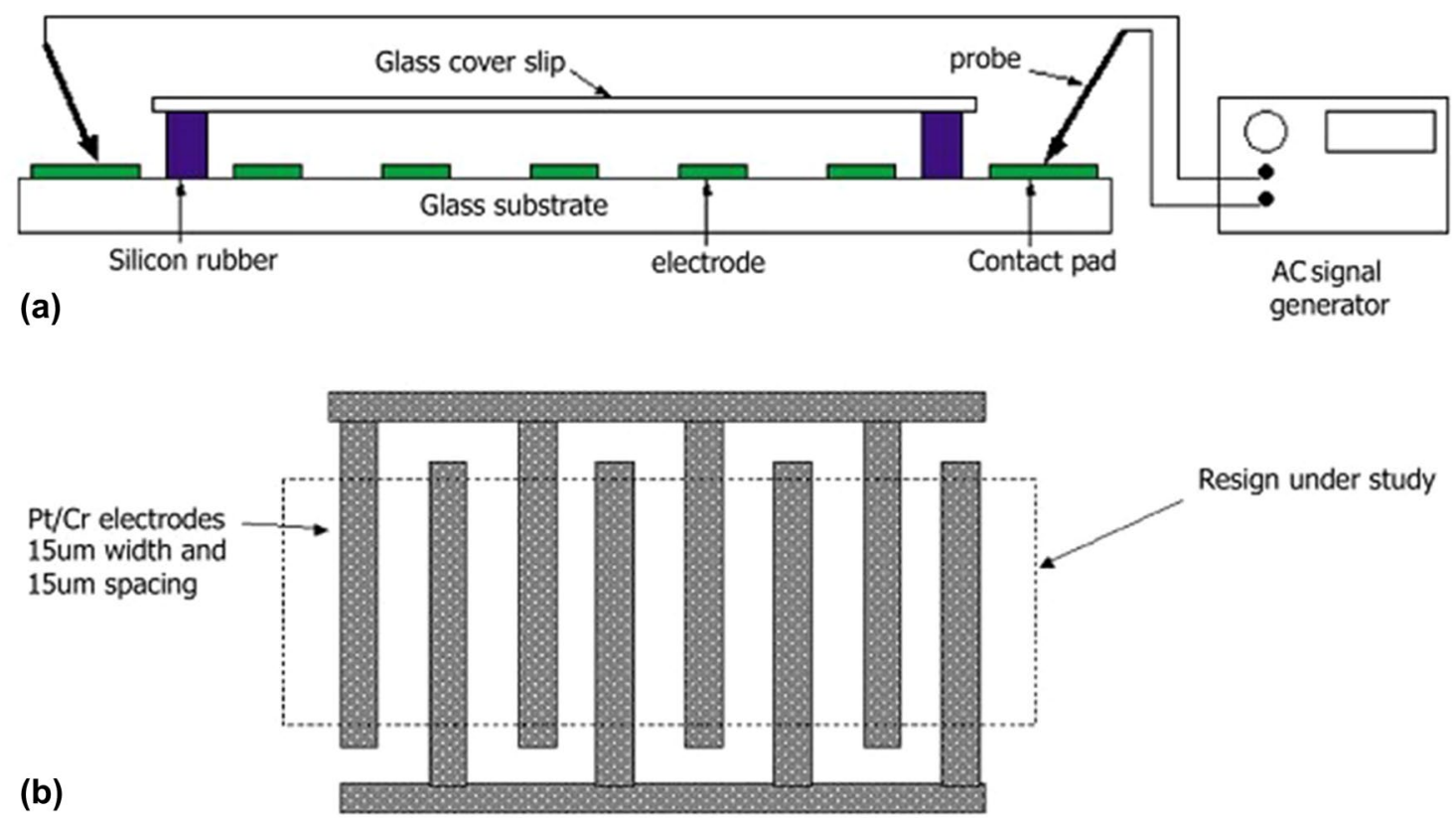

Fig. 7 a Microdevice developed by Li and Bashir [52], b superior view of the interdigitated electrodes. Reprinted with permission 
microorganisms can be handled in the microdevice and consequently separated from red and with globules using dielectrophoresis in low conductivity media (deionized water). The results showed that for a signal frequency of $20 \mathrm{MHz}, 92 \%$ of the microorganisms experienced a DEP+ force, being concentrated at the electrodes edges. Simultaneously, altered red globules experienced a DEP- force and were grouped at the microdevice centre, above the electrodes centre. The microdevice consisted in an assembly of interdigitated electrodes, coated with an isolation layer and a microfluidic chamber. The electrodes arrangement consisted in 5 electrodes pairs (width $=90 \mu \mathrm{m}$ and gap $=10 \mu \mathrm{m}$ ), coated by silica (isolation) to minimize the electrochemical reaction occurrence with the electrolyte and to allow the maximization of microdevice service lifetime.

The human blood plasma provides crucial information about disease diagnosis. The plasma is the liquid portion of the blood, being about $55 \%$ of overall blood content and it plays a critical role in several health problem treatments. Accordingly, various researchers proposed microdevices to perform blood plasma separation. Tripathi et al. [98] highlighted some advantages of portable devices including a faster analysis, requirement of low amounts of samples and reactants and ensuring an in loco, real time monitoring of the patient.

Chen et al. [16] developed a microdevice for blood plasma separation based on a gradual filtration process using a two-layer cell-capture/back-end filters arrangement. The first layer has pillars to provide small gaps between the second layer and a glass layer. The plasma flowed through the spacing, while the blood cells were retained due to the larger volume. The authors tested two filter configurations (straight line filter and square wave filter, with widths of $22 \mu \mathrm{m}$ and $5 \mu \mathrm{m}$, respectively_Fig. 8). The square wave filter exhibited superior performance. The microdevice was made of polydimethylsiloxane (PDMS) via soft lithography. The blood was dilute at different factors $(10,20,50)$ to evaluate the separation efficiency. The plasma separation efficiency increased with the dilution factor, decreasing with the gap height increment and being the separation efficiency close to $100 \%$.

It is worth mentioning the work by Rodrígues-Villareal et al. [82], who proposed a microfluidic separation device, which has the advantage of being able to work under high flow rates of blood. The device uses fluidic focusing and particle dispersion in the separation (Fig. 9). Also, the design employed a channel cross section reduction, narrowing the blood flow stream, enhancing the blood cell deformability. The narrow stream of blood cells flows from the wider channel to a lateral channel where the plasma was collected. The superior result, $97.05 \%$ of cell separation, was observed at higher flow rate $\left(200 \mu \mathrm{L} \mathrm{min}^{-1}\right)$ at $37^{\circ} \mathrm{C}$. All channels have a depth of $40 \mu \mathrm{m}$. The width of inlet and outlet was $400 \mu \mathrm{m}$, while the lateral channel presented an inlet zone $65 \mu \mathrm{m}$ wide and $800 \mu \mathrm{m}$ long and an outlet section $200 \mu \mathrm{m}$ wide and $2000 \mu \mathrm{m}$ long.

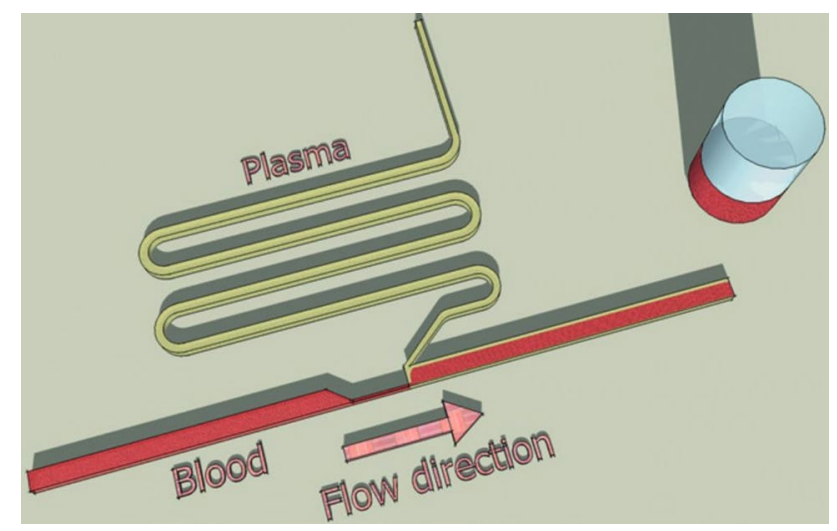

Fig. 9 Sketch of the microdevice. Blood direction and plasma separation after the channel constriction. Reprinted with permission from Rodrígues-Villareal et al. [82]
Fig. 8 Design of the: a cellcapture structures, $\mathbf{b}_{\mathbf{1}}$ straight line filter, $\mathbf{b}_{\mathbf{2}}$ square wave filter. Reprinted with permission from Chen et al. [16]

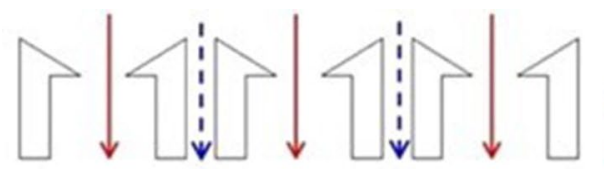

(a)

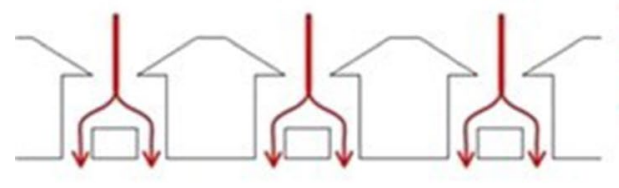

(b)

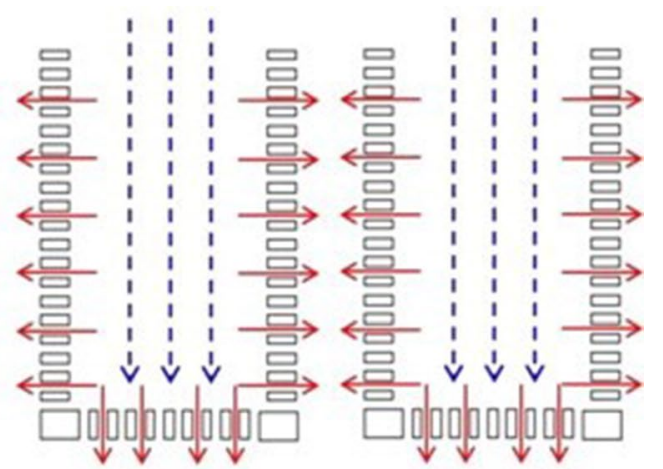

$\left(b_{2}\right)$

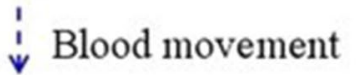

Plasma movement 
Vaghi et al. [100] applied surface functionalization in microchannels for viral RNA purification. The plane surfaces made of PDMS were modified to adsorb RNA. Careful chemical and morphological analyses were carried out in the modified surfaces, and the functionalization protocol that provided superior RNA adsorption was employed in the PDMS microdevices. Nam et al. [68] proposed a microdevice based on standing surface acoustic waves (SSAWs) for high purity separation of platelets from blood using whole blood without dilution. The device (Fig. 10) was composed by interdigitated transducers (IDTs), microchannels and hydrodynamic focusing technique. The sample and sheath flow rates were $0.25 \mu \mathrm{L} \mathrm{min}{ }^{-1}$ and $5 \mu \mathrm{L} \mathrm{min}^{-1}$, respectively. The platelets purity at outlet (A) reached $98 \%$.

Tripathi et al. [98] demonstrated the plasma separation using hydrodynamic separation in microchannels with size of orders of $\mathrm{mm}$. The authors demonstrated an interesting application of the Zweifach-Fung bifurcation law in length scales much superior than the suspended particle size. The microdevice worked under a constant flow rate of $0.15 \mathrm{~mL} \mathrm{~min}{ }^{-1}$. The authors evaluated the haematocrit level and the flow rate distributions. The results demonstrated a separation efficiency increment with the increase on flow rate and the dilution of the blood samples (i.e., the separation efficiency increased with the decrease on haematocrit level), achieving $100 \%$ of separation efficiency at low haematocrit levels. Figure 11 presents the process separation and the design of the T-shape microchannel. The device has a blood sample inlet and two outlets for plasma and concentrated blood cells. The authors used higher Peclet numbers to provide the formation of blood cell clustering. The cell agglomeration flowing near the microchannel bifurcation promoted the high efficiency separation.

Recently, Forchelet et al. [23] have developed a device for separating blood micro-samples using a basic microfluidic principle: laminar flow. The device allowed the separation of $25 \mu \mathrm{L}$ of undiluted blood samples in complete

(b)

(e)

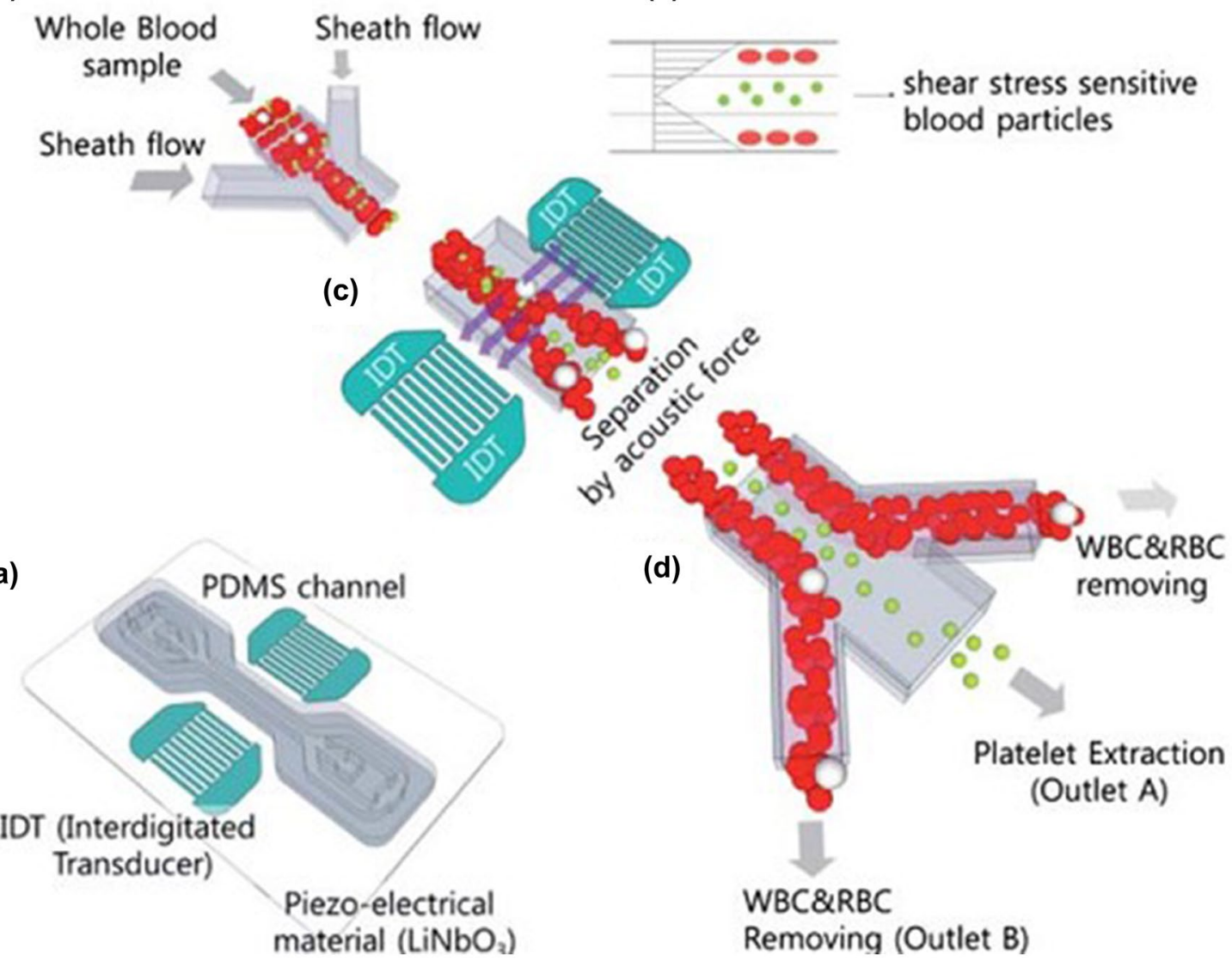

Fig. 10 Platelet separation from whole blood in a microdevice with acoustic system: a schematics of the acoustic device with a pair of IDTs, b whole blood sample is injected and hydrodynamically focused by two sheath flow layers, c separation of blood particles in the working region of SSAWs by means of a size-gradient man- ner-large particles (red and white blood corpuscles) are driven to the side of the channel instead of the small particles, $\mathbf{d}$ platelets are mainly sorted and collected through the center outlet, e platelets are designed to flow in the middle of the channel, where the shear effect is minimized. Reprinted with permission from Nam et al. [68] 
Fig. 11 Blood plasma separation process in a T-shape microchannel. Reprinted with permission from Tripathi et al. [98]

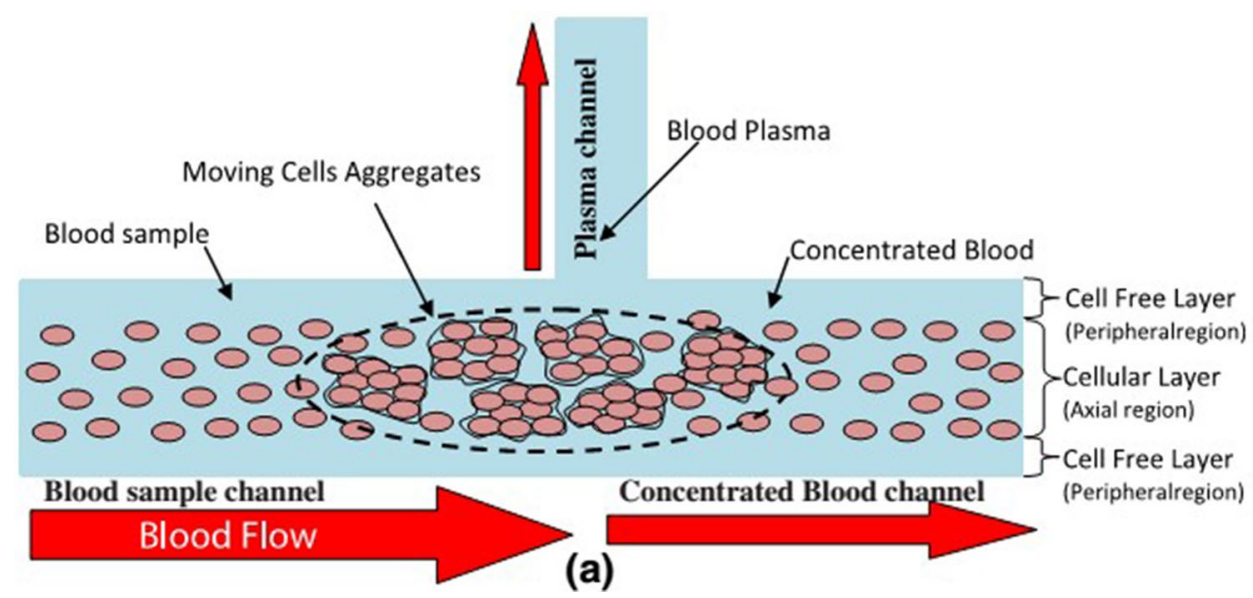

passive manner, without requiring additional or external equipment: both separation and pumping are passive mechanisms. The whole blood is separated into liquid and waste cells by using a separation principle which is based on viscosity differences. These differences are promoted by sedimentation and simultaneous capillary driven laminar flow. The manufacture of the microfluidic device was based on standard lithographic processes. The device consists of two parts: the top one contains the impression of the structure, while the bottom one is flat, which is modified with surfactant in order to obtain adequate capillary pressure in the device. Each area performs a specific function: separation of blood samples and ejection of a sample free of output cells with volume measurement, respectively. When flowing in the separation area, the cells present in the sample, thanks to the action of gravitational forces, sediment towards the bottom part of the channel, which does not present any complex structure.

\section{Water purification}

This section approaches recent advances in water treatment and desalination using membrane technology and electrochemical and photocatalytic microreactors.

\subsection{Membrane technology}

Membrane technology has been widely used in water purification and desalination. The great advantage of membrane technologies is the achievement of high-quality water without requiring relative less chemical treatment or energy consumption regarding traditional distillation methods. Membrane separation can be divided in low pressure operation: Microfiltration (MF) and Ultrafiltration (UF); and high pressure operation: Nanofiltration (NF) and Reverse Osmosis (RO). The main characteristics of these membranes are summarized in Table 1.

Low pressure-driven processes (MF and UF) are performed in porous membranes and are usually employed as pre-treatment stages to remove suspended particles and macromolecules. Convective transport and size exclusion mechanisms prevail in MF and UF. In MF, small particulate solids, microbial cells and large colloids are retained. UF membranes reject colloids, emulsion, proteins and macromolecules [78]. In NF and RO membranes, molecular diffusion transport and solute-membrane matrix interactions occurs, including size and charge exclusion, approaching separation at molecular and ionic levels [58]. In what follows, the main features of high pressure-driven membranes will be described.
Table 1 Main characteristics of membrane technologies with representative ranges

\begin{tabular}{llll}
\hline Process & Driving force range ${ }^{\mathrm{a}}$ & Membrane type, pore size range & $\begin{array}{l}\text { Molecular weight } \\
\text { cut-off, MWCO } \\
(\mathrm{Da})^{*}\end{array}$ \\
\hline MF & $0.5-2 \mathrm{bar}$ & Porous, $0.1-0.8 \mu \mathrm{m}^{\mathrm{a}}$ & $>100,000^{\mathrm{c}}$ \\
UF & $2-6 \mathrm{bar}$ & Porous, $1-10 \mathrm{~nm}^{\mathrm{a}}$ & $>1000^{\mathrm{a}}$ \\
NF & $5-15 \mathrm{bar}$ & Semipermeable, $\leq 1 \mathrm{~nm}^{\mathrm{b}}$ & $200-500^{\mathrm{a}, \mathrm{b}}$ \\
RO & $10-60 \mathrm{bar}$ & Semipermeable & $<200^{\mathrm{c}}$ \\
\hline
\end{tabular}

*The MWCO represents the chemical species molecular weight rejected (or retained) by the membrane

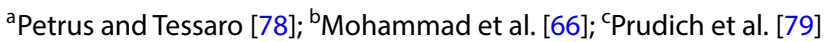


Fouling is a main limiting factor in NF and RO applications and can be divided in surface and internal fouling. The fouling mechanism differs from low pressure-driven to high pressure-driven membranes. For MF and UF, pore clogging or adsorption are more common. For NF and RO, surface fouling is more frequent due to the dense nature of the membranes [58]. Depending on feed water composition and their interactions with the membrane, fouling can be irreversible [40]. Accordingly, feed water pre-treatment is necessary to prolong membrane lifetime and prevent its fouling. Pre-treatment normally is based on chemical coagulation, filtration (including UF and MF) and scaling control. Membrane fouling can occur due to inorganic or mineral scaling, organic fouling, microbial growth and colloidal and particulate deposition $[4,58]$. Anti-fouling pretreatment strategies are widely discussed by Mohammad et al. [66] for NF and by Badruzzaman et al. [4] and Jiang et al. [40] for RO. Several metal and metal oxide nanoparticles (zeolites, titanium dioxide) have been incorporated into polymeric matrix of NF membranes, improving mechanical and thermal characteristics, anti-fouling and anti-bacterial properties. Titanium dioxide has been widely used as antifouling in membrane preparation, due to its hydrophilicity, repeling hydrophobic foulants [19] and photocatalytic behavior, aiding the degradation of organic compounds from water. Carbon-based nanomaterials (e.g., carbon nanotubes, CNTs and graphene) are also employed in NF membranes. These materials present hydrophobic and excellent water transport characteristics due to smooth inner walls. Mixed matrix membranes, prepared by CNT addition, exhibit enhanced separation and antifouling characteristics. Borg et al. [11] and Majumder et al. [57] performed molecular dynamics (MD) simulations in CNT with diameters below $10 \mathrm{~nm}$. Both researches observed water fluxes about 2-5 orders of magnitude greater than Hagen-Poiseuille predictions. Recently, metal-organic frameworks (MOF) emerged as potential nanoporous material for NF membrane preparation. The main characteristics are high surface area-to-pore volume ratio, tunable chemical structure and surface properties. Sorribas et al. [94] observed an increment in the solvent permeance into MOF membrane regarding a conventional polymeric membrane without sacrificing the rejection due to preferential flow paths. However, structural stability and species separation performance should be further improved.

Traditionally, water desalination is carried out using Multistage Flash (MSF) or RO. The two main issues related to RO membranes are the membrane fouling and the energy consumption (about $44 \%$ of the produced water cost) related to the high operating pressure. Recently, hybrid processes using NF as a pre-stage for RO desalination allowed an increment about $60 \%$ in water production and costs reduction around 30\% regarding traditional
RO and MSF processes [66]. Song et al. [92] used UF-NF pre-treatment process for total organic carbon (TOC) removal, removing $96.3 \%$ of the TOC. Membrane fouling was observed even after chemical cleaning. A dual stage NF process was investigated by Harrison et al. [34] using bench and pilot scales by Long Beach Water Department to produce potable water, resulting in the reduction of energy consumption regarding a NF-RO unit. The energy consumption in $\mathrm{RO}$ process can also be reduced using energy recovery systems, such as Pelton wheel or pressure exchangers using the brine stream [58]. Khawaji et al. [45] reported an energy consumption reduction from 6-8 to $4-5 \mathrm{kWh} \mathrm{m}^{-3}$ and a potential optimization to $2 \mathrm{kWh} \mathrm{m}^{-3}$ when using energy recovery systems. Furthermore, hybrid systems using renewable energy sources have been used, too. Latorre et al. [48] observed a power input reduction $20 \%$ lower than the original RO plant when using a wind turbine. Gökçek [28] evaluated a hybrid system composed by a wind-photovoltaic-diesel-battery in a small-scale RO. The results showed an effective method for production of potable water in remote areas with good wind and solar power characteristics.

Despite the advances in membrane technology, further developments are required in membrane fouling control, brine disposal and new materials for membrane, e.g. the use of titanium dioxide allows a synergetic effect of photodegradation of organic compounds from water, or the use of CNTs improving the permeate flux across the membrane. The use of hybrid systems, including mechanical energy recovery devices and renewable energy sources, presents great potential aiming costs reduction in water treatment. Numerical simulations appear as fundamental tools for development and analyses of such systems, approaching from molecular dynamics to macroscopic energy and exergy analyses.

\subsection{Electrochemical technology}

Electrochemical technologies appear as a promising technique for wastewater treatment. The main challenge is to reduce the energy consumption, especially in the purification of low-conductive affluents. The energy consumption is directly related to the overall electrical circuit ohmic resistance, or ohmic drop, and it strongly depends on the electrode cell design. The ohmic drop is due to energy dissipation, deprecating the cell performance and it is directly related to the inter-electrode (IE) gap, i.e. the spacing between the electrodes. The main contribution to ohmic drop increment is the low conductivity of electrolytes regarding other system components. The electrolyte conductivity can be largely increased by the increment in electrolyte concentration. However, this leads to secondary pollution, since the inorganic compounds were carried 
out in effluent resulting in operational costs increment [79, 84]. Recently, the use of microfluidic devices allowed the use of small IE gaps, usually below $1000 \mu \mathrm{m}$ resulting in superior performance. Microfluidic devices also present higher current efficiencies in oxidation processes due to the mass transfer enhancement [84-86].

Continuous electrochemical reactors present two main flow arrangements (Fig. 12): Flow-By (FB) and FlowThrough (FT). In the FB configuration, the electrolyte fluid flows between parallel-plate electrodes. The reduction of IE gap increases the pressure drop, limiting the flow rate. Moreover, this configuration could present clogging problems when working under high current densities and gas evolution reactions [12]. In the FT configuration, the electrolyte fluid flows across 3D electrodes (meshes, foams or packings). This configuration allows advantages of simultaneous minimization of ohmic drop and maximization of mass transfer, avoiding the operational problems observed in the FB. Moreover, the addition of activated carbon or metal particles inside the IE gap contributes to the enhancement in conductivity, mass transfer and adsorption of the pollutants, allowing superior removal performance $[106,109]$. The electrochemical oxidation of pollutants is generally divided in two categories: direct and indirect oxidation. In the first, the electron is directly transferred on the anode. In the indirect mechanism, radical species are generated from water electrolysis, as for example, the electro-Fenton process [109].

In 3D electrodes, three mechanisms could act in the electrochemical oxidation: adsorption/electrosorption, catalytic degradation by oxidation and electrocoagulation. Adsorption and electrosorption occur due to the

(a)

Flow-By (FB)

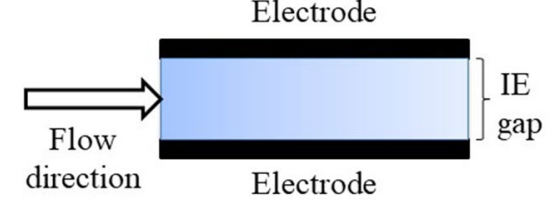

(b)

Flow-Through(FT)

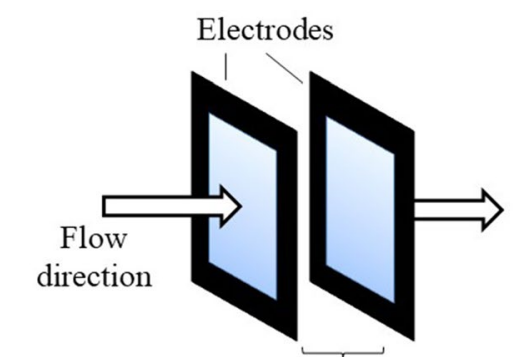

IE gap

Fig. 12 Electrochemical reactor configuration: a Flow-By; b FlowThrough

packing high specific area combined with the electric charge. Catalytic degradation by oxidation is due to the formation of polarized microelectrodes, comprehending direct and indirect oxidation. The addition of some metals, e.g., $\mathrm{Fe}^{2+}$, induces electro-Fenton reactions (indirect oxidation), enhancing the catalytic degradation performance. Electrocoagulation is used to remove macromolecular hydrophobic substances. It is based on the use of iron or stainless steel anodes or particle electrode producing iron hydroxide. The major drawback is the iron sludge generation, requiring a final disposition.

The anode material plays a fundamental role affecting the catalyst activity and selectivity and the current efficiency. Thin oxide films $\left(\mathrm{PbO}_{2}, \mathrm{SnO}_{2}\right)$ experience activity loss due to surface fouling or relative short service lifetime [5]. Metal oxides, including $\mathrm{RuO}_{2}, \mathrm{IrO}_{2}$, present long service life, good activity and are relatively inexpensive. Boron-doped diamond (BDD) appears as an ideal anode for wastewater oxidation, due to its long lifetime, stability and mechanical characteristic; however, it is more expensive than metal oxides [109]. The cathode is usually composed by metals or carbon materials, including stainless steel, activated carbon fibre and graphite. Granular activated carbon (GAC) is the most frequently used particle electrode due to its advantages of large specific area, pore structures and adsorption loading capacity [7]. The use of GAC in wastewater treatment promotes a synergetic combination of adsorption and electrosorption, promoting high removal of organics.

Future perspectives include supported catalysts. Common catalyst support includes alumina, molecular sieves, zeolites and ion-exchange resins. Heterogeneous Fenton catalyst solves the drawback of iron sludge disposal after treatment, eliminating additional separation steps [109]. Arenas et al. [2] manufactured a 3D-printed, highly ordered porous electrode, made of a nickel-coated stainless steel. The printed electrode was used in electrochemical cell applications. Its performance was evaluated by optical microscopy, electrochemical and mass transport characteristics. The 3D-printed electrode mesh exhibited tailored composition, good characteristics of catalytic activity, active surface area, fluid flow and mass transfer. The authors highlighted the potential use of multi-material additive manufacturing, opening a possibility of a versatile fabrication of specific designed electrochemical reactors.

Scialdone et al. [87] listed some advantages of microdevices over macroscale reactors, including: easier scale-up procedure using parallelization; fast operating conditions optimization, due to the small IE gaps and relative short residence times; and the potential use of multistage systems with two or more electrochemical cells arranged in series working under optimal current densities and, consequently, minimizing the treatment time. Scialdone et al. 
[87] also proposed a micro-electrochemical cell composed by two plate electrodes of BDD/Nb (anode) and nickel (cathode). The IE gap was ranged from 50 to $75 \mu \mathrm{m}$. The oxidation of formic acid (FA) was performed. High levels of FA oxidation were observed for low flow rates (long residence times) and high current densities. An abatement level of $99 \%$ of formic acid was obtained at $13.3 \mathrm{~mA} \mathrm{~cm}^{-2}$, $0,05 \mathrm{~mL} \mathrm{~min}^{-1}$ for a IE gap of $50 \mu \mathrm{m}$.

Scialdone et al. [84, 86] employed macro- and microfluidic cells for the electrochemical abatement of chloroacetic acid (CAA) using direct and indirect oxidation pathways. The system I was composed by a stirred batch glass cell with electrodes plates of $3 \mathrm{~cm}^{2}$ (Pt sheet or BDD thinfilm anode and a carbon-PTFE-air diffusion cathode, where PTFE stands for Polytetrafluoroethylene) with an IE gap of $1 \mathrm{~cm}$. The system II consisted in undivided filter-press reactor (ElectroCell AB, Tarm, Denmark) working in continuous regime. The electrode plates have $10 \mathrm{~cm}^{2}$ of area. Ti/ $\mathrm{IrO}_{2}-\mathrm{Ta}_{2} \mathrm{O}_{5}$ or BDD anode and compact graphite, $\mathrm{Ag}, \mathrm{Cu}$ or stainless steel (AISI 304) cathode were used. The IE gap was $4 \mathrm{~mm}$. Also, a single-pass microreactor (System III) was used, operating under $0.05-0.6 \mathrm{~mL} \mathrm{~min}^{-1}$, equipped with the ElectroCell $A B$ jointly with PTFE spacer providing IE gaps ranging between 50 and $100 \mu \mathrm{m}$. The electrode working areas were $5 \mathrm{~cm}^{2}$. A superior CAA abatement was observed in the microfluidic cell for the indirect oxidation, even in the absence of supporting electrode (an essential key in the macro-cells to obtain a significant abatement). The direct oxidation path provided high abatement levels in macro and micro-cells. Coupled oxidation processes were evaluated, leading to superior CAA abatement performances regarding single processes. The coupled process using a BDD anode and graphite cathode with iron sulfate resulted in faster and higher abatement level (above $90 \%$ ) under low current densities $\left(<5 \mathrm{~mA} \mathrm{~cm}^{-2}\right)$ in the microfluidic reactor with a IE gap of $100 \mu \mathrm{m}$.

Perez et al. $[76,79]$ proposed a flow-through microreactor (FTMR) (Fig. 13) with different IE gaps (6000-1000 and $400 \mu \mathrm{m}$ ) using electrolyte conductivity ranging from 0.7 to $40.1 \mathrm{mS} \mathrm{cm}^{-1}$. The microreactor was composed by $\mathrm{RuO}_{2} / \mathrm{IrO}_{2}$ coated titanium-mesh cathode of total size $8 \times 9.5 \mathrm{~cm}$. The surface area was $52.8 \mathrm{~cm}^{2}$. The anode was composed by a thin-film BDD electrode supported in a niobium mesh with total size of $8 \times 9.5 \mathrm{~cm}$. The estimated anode surface area was $49.5 \mathrm{~cm}^{2}$. The FTMR performance was compared with a stirred tank (ST) reactor with parallel plate electrodes (IE gaps of 25,000-6000 and $1000 \mu \mathrm{m}$ ) working with similar electrolyte concentrations. The FTMR required a lower cell voltage regarding the ST. The IE gap reduction did not influence the pressure drop. The electric charge was 4-10 times lower and the energy consumption was 6-15 times lower for the mineralization of $100 \mathrm{ppm}$ of the clopyralid. The estimated mass transfer coefficient

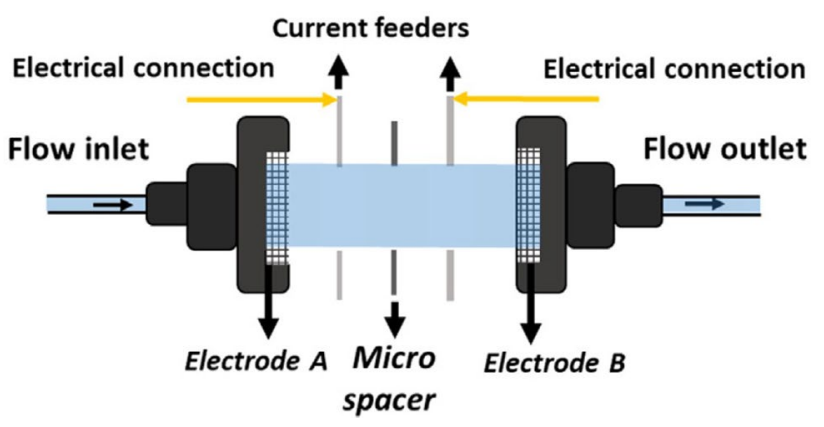

Fig. 13 FT microfluidic reactor configuration proposed by Pérez et al. [77]. Reprinted with permission

was $70 \%$ higher than in a conventional reactor. The ohmic resistance in the $0.7 \mathrm{mS} \mathrm{cm}^{-1}$ solution was $6 \Omega$ at $400 \mu \mathrm{m}$, against $346 \Omega$ for the ST at 25,000 $\mu$ m (a common gap in lab-scale reactor). For similar IE gap of $1000 \mu \mathrm{m}$, the ohmic resistances for FTMR and ST were $11 \Omega$ and $61 \Omega$, respectively.

Electrochemical microreactors appear as promising technology for water treatment. The FT design represents a feasible configuration for scaling-up to achieve high throughputs. The combination of continuous FTMRs operating in series could allow the operation under superior electric performance. The use of combined oxidative processes provide superior organic abatement, appearing as an interesting strategy. These features combined with the numbering-up could lead to large throughput and efficient modular plants. Moreover, the advancement of 3D printing techniques lined up with numerical simulations to obtain optimized devices and flow distributors appears as promising tools in the field of electrochemical microreactors.

\subsection{Photocatalytic technologies}

Photocatalytic processes have been receiving great attention in the fields of water treatment, chemical synthesis and medicine [101]. Photocatalysis is a series of oxidation-reduction reactions, driven by photo-excited electron, that are activated by photon absorption carrying energy equal, or higher than, the band-gap energy of the catalyst [101, 104]. Two main oxidation pathways were observed experimentally: the hole-driven and the electron-driven. In the hole-drive pathway, oxidized products are obtained from the generation of a hole in the valence band promoted by the photon carrying an energy amount greater than the semiconductor photocatalyst bandgap. The electron-driven oxidation is carried out by excited electrons captured by the dissolved oxygen, resulting in a sequence of oxidation and reduction reactions, producing as intermediate peroxide 
hydrogen, and consequently providing more hydroxyl radicals. The most used photocatalyst is the titanium dioxide $\left(\mathrm{TiO}_{2}\right)$, since it is chemically and biologically inert, high efficient and stable, safe and nontoxic [15]. As irradiation source, ultraviolet (UV) light-emitting diode (LED), UV lamp and also solar light can be used [104].

Photocatalytic reactors stand out as a promising technology due to the decomposition of a wide range of organic compounds into innocuous products by the use of UV or sunlight irradiation [104]. The photocatalytic efficiency depends on mass transfer-related to the contaminant particles motion to the catalytic surface, directly related to the surface area-to-volume ratio $(A / V)$; photon transfer-the delivery of the photon to the catalytic sites, ideally the catalytic surface requires uniform radiation; and the available dissolved oxygen. Often, these limitations are observed in conventional bulk reactors as discussed by Heggo and Ookawara [35] and Van Gerven et al. [101]. In order to overcome these issues, optical microdevices have been developed. They lie on Optofluidics, an emerging area aiming the synergetic exploitation of optics, photonics and microfluidics.

Currently, the photocatalytic purification of water is performed in two classes of conventional bulk reactors: Slurry reactors (SR) - with suspended nanoparticles of photocatalysts in the liquid, resulting in large $A / V$ and good mass transfer rates (this configuration experiences light scattering and absorption by the suspended particles, resulting in low photon transfer and the necessity of nanoparticles filtration); Immobilized Reactors (IR) - the photocatalyst is immobilized on substrates forming a wall coated surface. Good photon transfer rates and no requirement of additional filtration are the main advantages, although, low $\mathrm{A} / \mathrm{V}$ results in poor mass transfer. Other reactor configurations were proposed by using optical fibre and oxygen/oxygen peroxide feed. However, none of the proposed design succeed all three major limitation issues.

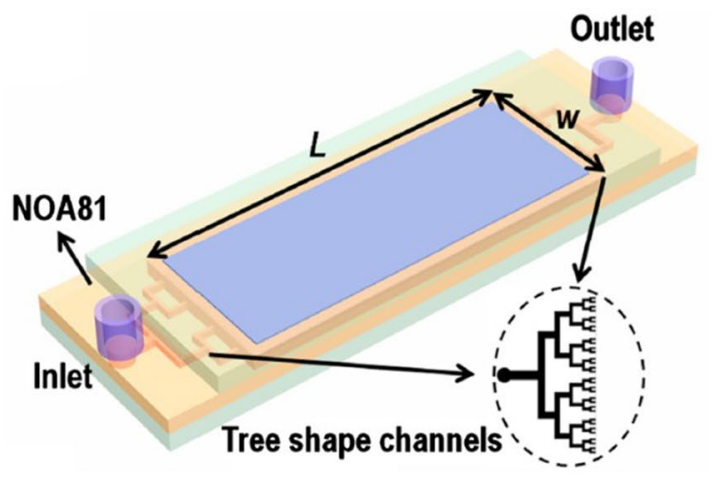

Photocatalytic microreactors (MRs) present advantages over bulk reactors including large surface area-to-volume ratio, diffusion path reduction, uniform residence time and irradiation, short residence time and enhancement of photocatalyst life cycle. The large A/V results in more effective contact among reactants and catalysts. The magnitude order of $\mathrm{A} / \mathrm{V}$ for microdevices range from 10,000 to $300,000 \mathrm{~m}^{2} \mathrm{~m}^{-3}$ to $<600 \mathrm{~m}^{2} \mathrm{~m}^{-3}$ from bulk reactors [103]. Also, the use of porous nanoparticles could enlarge even more the A/V. The short residence time is a consequence of the large $A / V$ and short diffusion path, resulting in enhancement of reaction rate constant up to 10,000 times the conventional reactors [50]. Significant pollutant degradation levels (over 90\%) were observed $[51,103]$ in MR operating in order of tens of seconds against several hours required by bulk reactors [73]. In MRs the photocatalyst is usually immobilized as a coated film and the fluid feed flows over this layer. This layout allows a uniform irradiation and high illumination efficiency. Furthermore, the own flow stream refreshes the coated surface, improving the catalyst life cycle. Wang et al. [103] reported that photocatalyst can last for several hundreds of runs against only 10 runs of bulk reactors. Accordingly, the use of optimal microdevices could treat most of pollutants in only one run, without the need of multiple passes through the reactor, a common strategy used in bulk reactors $[101,104]$.

Lei et al. [51] manufactured a planar microreactor (PMR) to study the degradation of methylene blue using solar radiation by means of three setups: traditional microreactor and two $\mathrm{TiO}_{2}$-coated PMR (single and dual coating, Fig. 14). Planar microreactors consist in a rectangular reaction chamber with two coatings, placed in superior and inferior walls, separated by the liquid layer height. The degradation efficiency experimentally observed was $94 \%$ for a residence time of $36 \mathrm{~s}$, while the reaction rate constant increases over 100 times regarding conventional reactors and the reaction rate decreases with the increase of the residence time. This behaviour can be attributed to

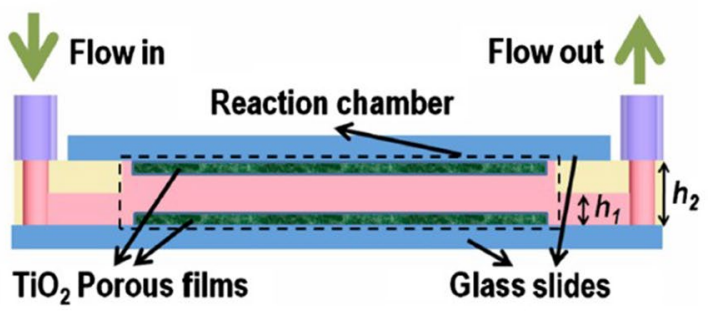

Fig. 14 Planar microreactor configuration proposed by Lei et al. [51]. Reprinted with permission 
mass transfer efficiency and oxygen availability. The $\mathrm{TiO}_{2}$ coating thickness was also investigated. For the single coat, the degradation performance increased with the film thickness from 0.5 to $2.0 \mu \mathrm{m}$. For the dual-layer $\mathrm{TiO}_{2}$ coating the degradation performance reached a maximum for a $1.0 \mu \mathrm{m}$ film thickness. Despite the good performance of the PMR, the main limitations were the oxygen deficiency and the low light utilization efficiency. In order to overcome the irradiation issues another PMR was proposed by Wang et al. [103] (Fig. 15) using at the chamber bottom a nanoporous coating of $\mathrm{BiVO}_{4} /$ Indium-Tin Oxide (ITO). The $\mathrm{BiVO}_{4}$ has high photocatalytic activity, enhancing the solar irradiation usage. In the superior chamber wall an ITO glass was used, another ITO glass coating as substrate while as the spacer and sealant was used NOA 81 adhesive layer. A polarity bias voltage scheme was used, enabling the control of the oxidation pathway (electron or hole-driven). Furthermore, the synergistic effect of photo- and electrocatalysis overcame the oxygen deficiency. The proposed photo-electrocatalytic microreactor showed potentiality to be scaled up for high-performance water purification.

Meng et al. [62] presented a photocatalytic microreactor by using electrospun nanofibrous $\mathrm{TiO}_{2}$. The proposed design has the advantages of shorter diffusion distance, high photocatalytic activity mostly due to the higher A/V compared to $\mathrm{TiO}_{2}$ films. The degradation performance was evaluated for a residence time range from 12 to $53 \mathrm{~s}$. For a residence time of $53 \mathrm{~s}$, the degradation rate observed for fiber and film microreactors were $>99 \%$ and $\approx 40 \%$, respectively. Furthermore, the specific reaction rate constant increased with the residence time (from 4.06 to $5.20 \mathrm{~min}^{-1}$ ) in the fiber microreactor, in contrast with the reduction observed in the film microreactor (from 1.5 to $\left.0.54 \mathrm{~min}^{-1}\right)$.

Leblebici et al. [50] compared the performance of 12 photocatalytic reactor designs including a microreactor.
The authors proposed a benchmark based on the photocatalytic space-time yield, PSTY $\left(\mathrm{m}^{3}\right.$ water day ${ }^{-1}$ $\mathrm{m}^{-3}$ reactor $\mathrm{kW}^{-1}$ lamp), that relates the main operating parameters, as the rate of wastewater processed, the reactor volume, the apparent reaction rate and the lamp power. The overall superior performance was noticed for the tubular slurry reactor, scoring a PSTY of 0.72 , due to the plug flow behaviour and the good mass transfer characteristic from slurry systems. The best performances of the immobilized reactors were the Spinning Disc Reactor (PSTY of 0.0149) and the microreactor (PSTY $=0.0108$ ). The authors emphasized that with a lamp power optimization (e.g., use of a LED arrays), the MR could result in a PSTY of 13 (over 20 times the superior PSTY observed), standing out the great potential of the microdevice. The MR scale-up procedure for photocatalytic application must include an efficient light distribution that addresses a major challenge in numbering-up. Another aspect to be mentioned is the reaction rate, $k$, provided by the different reactor designs. The MR exhibited $k$ of magnitude order of $10^{6}$ day $^{-1}$ against $10^{1}-10^{2}$ day $^{-1}$ of the other reactors. Also, the lamp power per volume unit of the MR was about 1000 times greater than the other designs.

Optimal photocatalytic microreactors must encompass enhanced mass and photon transfer mechanisms, high efficiency irradiation usage and oxygen supply approaches. The numbering-up could be used as a smart scale-up strategy to achieve large rates for water treatment, therefore, uniform distribution schemes for flow and irradiation through all microdevices must be considered. New combinations of nanoporous and nanofibrous catalyst coating and integration of electro-photon catalysis jointly with high efficiency UV-LED arrays stand out as promising technologies for the development of high performance scalable microdevices.
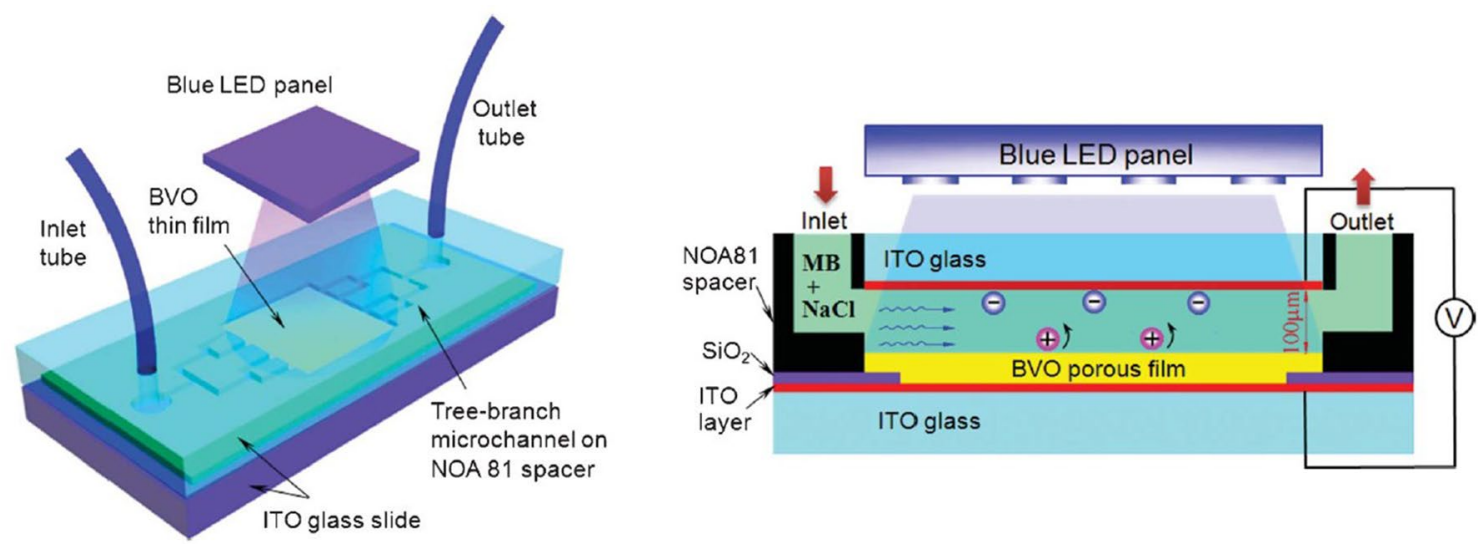

Fig. 15 Planar photocatalytic microreactor proposed by Wang et al. [103]. Reprinted with permission 


\section{Conclusions}

As demonstrated in this review, intensification of liquid-liquid extraction can take advantage from the small dimensions of microfluidic devices. These advantages are intrinsically related to the short path lengths, thus high interfacial area between the phases can improve efficiency of extraction, which reduces chemical waste products. It should be noted, despite the benefits in microfluidic devices, some limitation could be found such as difficulty phase separation, restricted methods for analysis and the limited range of flow.

Regarding the area of biotechnology, it is one of the most successful applications of microfluidics. In this review, it is shown that microfluidic devices can be used in the efficient separation of biological samples usually present in processes related to, among others, DNA, RNA, acid drugs, parallel genetic analysis, blood samples, disease diagnosis or blood plasma. For separation of biological samples, techniques such as extraction, electrophoresis and hydrodynamics can be used together with simple microchannel design. The channels can range from micrometric to millimeter scale, which facilitates the manufacturing process of microfluidic devices and their use.

Finally, micro and nanotechnology have substantiated the development and optimization of water purification processes including membrane technology, electrochemical and photocatalytic treatments. Further developments in membrane technology are required to control membrane fouling and to manufacture new membrane materials. The use of smart materials appears as an interesting alternative, including membrane coating with titanium dioxide, promoting a synergetic photo-degradation effect of organic species, or the use of carbon nanotubes to enhance the permeate flux. Electrochemical microreactors with flow-through configuration are feasible for scaling-up to achieve high throughputs. The use of combined oxidative processes is an interesting strategy. The advances in additive manufacturing (3D printing) emerges as promising tool in the field of electrochemical microreactors, allowing the fabrication of optimized and customized microdevices and also, the design and assembly of efficient modular plants based on the numbering-up concept. Optofluidic devices allowed the combination of the key factors for an efficient photocatalytic process: enhanced mass and photon transfer, high efficiency irradiation usage and oxygen supply. The combination of new nanocatalysts and the integration of electro-photon processes and high efficiency UV-LEDs appear as potential technology to be used in high performance microreactors.

Authors' contributions HSS was in charge of writing Sects. 3 and 5. JLSJ was in charge of writing Sects. 4 and 5. BA was in charge of writing Sects. 2 and 5. JOC was in charge of writing the Abstract, Sects. 1 and 5, asked for permission for reprinting the corresponding figures and was the corresponding author. All authors read and approved the final manuscript.

Funding HSS would like to thank the National Postdoctoral Program (PNPD/Capes) and the Unicamp Scholarship Program for the funding made available in conducting this research.

Availability of data and supporting materials section Data sharing not applicable to this article as no datasets were generated or analysed during the current study.

\section{Compliance with ethical standards}

Conflict of interest The authors declare that they have no competing interests.

\section{References}

1. Abbasi A, Rahbar-Kelishami A, Ghasemi MJ (2018) Development of a microfluidic-chip system based on parallel flow for intensified Gd(III) extraction from nitrate media using cationic extractant. J Rare Earths 36(11):1198-1204

2. Arenas LF, de León CP, Walsh FC (2017) 3D-printed porous electrodes for advanced electrochemical flow reactors: a $\mathrm{Ni} /$ stainless steel electrode and its mass transport characteristics. Electrochem Commun 77:133-137

3. Assmann N, Ładosz A, Rudolf von Rohr P (2013) Continuous micro liquid-liquid extraction. Chem Eng Technol 36(6):921-936

4. Badruzzaman M, Voutchkov N, Weinrich L, Jacangelo JG (2019) Selection of pretreatment technologies for seawater reverse osmosis plants: a review. Desalination 449:78-91

5. Bagastyo AY, Radjenovic J, Mu Y, Rozendal RA, Batstone DJ, Rabaey K (2011) Electrochemical oxidation of reverse osmosis concentrate on mixed metal oxide (MMO) titanium coated electrodes. Water Res 45(16):4951-4959

6. Barikbin Z, Rahman MT, Parthiban P, Rane AS, Jain V, Duraiswamy S, Lee SHS, Khan SA (2010) Ionic liquid-based compound droplet microfluidics for 'on-drop'separations and sensing. Lab Chip 10(18):2458-2463

7. Berenguer R, Marco-Lozar JP, Quijada C, Cazorla-Amorós D, Morallon E (2010) Electrochemical regeneration and porosity recovery of phenol-saturated granular activated carbon in an alkaline medium. Carbon 48(10):2734-2745

8. Berthier J, Tran VM, Mittler F, Sarrut N (2009) The physics of a coflow micro-extractor: interface stability and optimal extraction length. Sens Actuators A 149(1):56-64

9. Bisceglia $\mathrm{E}$, Cubizolles $\mathrm{M}$, Trainito $\mathrm{Cl}$, Berthier J, Pudda $\mathrm{C}$, Français O, Mallardc F, Le Pioufle B (2015) A generic and label free method based on dielectrophoresis for the continuous 
separation of microorganism from whole blood samples. Sens Actuator B Chem 212:335-343

10. Blumberg R (1988) Liquid-liquid extraction. Academic Press, New York

11. Borg MK, Lockerby DA, Ritos K, Reese JM (2018) Multiscale simulation of water flow through laboratory-scale nanotube membranes. J Membr Sci 567:115-126

12. Bouzek $K$, Jiřičný $V$, Kodým $R$, Křištál J, Bystroň $T$ (2010) Microstructured reactor for electroorganic synthesis. Electrochim Acta 55(27):8172-8181

13. Brody JP, Yager P (1997) Diffusion-based extraction in a microfabricated device. Sens Actuators A Phys Sens 58(1):13-18

14. Burns JR, Ramshaw C (2001) The intensification of rapid reactions in multiphase systems using slug flow in capillaries. Lab Chip 1(1):10-15

15. Carp O, Huisman CL, Reller A (2004) Photoinduced reactivity of titanium dioxide. Prog Solid State Chem 32(1-2):33-177

16. Chen J, Chen D, Yuan T, Chen X, Xie Y, Fu H, Cui D, Fan X, Oo MKK (2014) Blood plasma separation microfluidic chip with gradual filtration. Microelectron Eng 128:36-41

17. Ciceri D, Mason LR, Harvie DJ, Perera JM, Stevens GW (2014) Extraction kinetics of Fe(III) by di-(2-ethylhexyl) phosphoric acid using a Y-Y shaped microfluidic device. Chem Eng Res Des 92(3):571-580

18. Coulson JM, Richardson JF (2002) Chemical engineering particle technology and separation processes, vol 2, 6th edn. Butterworth-Heinemann, Woburn

19. Damodar RA, You SJ, Chou HH (2009) Study the self cleaning, antibacterial and photocatalytic properties of $\mathrm{TiO}_{2}$ entrapped PVDF membranes. J Hazard Mater 172(2-3):1321-1328

20. Dai S, Luo J, Li J, Zhu X, Cao Y, Komarneni S (2017) Liquidliquid microextraction of $\mathrm{Cu}^{2+}$ from water using a new circle microchannel device. Ind Eng Chem Res 56(44):12717-12725

21. Das D, Duraiswamy S, Yi Z, Chan V, Yang C (2015) Continuous droplet-based liquid-liquid extraction of phenol from oil. Sep Sci Technol 50(7):1023-1029

22. Dessimoz AL, Cavin L, Renken A, Kiwi-Minsker L (2008) Liquid-liquid two-phase flow patterns and mass transfer characteristics in rectangular glass microreactors. Chem Eng Sci 63(16):4035-4044

23. Forchelet D, Béguin S, Sajic T, Bararpour N, Pataky Z, Frias M, Grabherr S, Augsburger M, Liu Y, Charnley M, Déglon J, Aebersold R, Thomas A, Renaud P (2018) Separation of blood microsamples by exploiting sedimentation at the microscale. Sci Rep 8(1):14101

24. Fries DM, Voitl T, von Rohr PR (2008) Liquid extraction of vanillin in rectangular microreactors. Chem Eng Technol Ind Chem PI Equip Process Eng Biotechnol 31(8):1182-1187

25. Fritsch RJ, Krause I (2003) Electrophoresis. In: Caballero B (ed) Encyclopedia of food sciences and nutrition, 2 edn. Academic Press, New York, pp 2055-2062. ISBN 9780122270550

26. Fukuyama T, Rahman MT, Kamata N, Ryu I (2009) Radical carbonylations using a continuous microflow system. Beilstein J Org Chem 5:34

27. Geyer K, Codee JD, Seeberger PH (2006) Microreactors as tools for synthetic chemists - the chemists' round-bottomed flask of the 21 st century? Chem Eur J 12(33):8434-8442

28. Gökçek M (2018) Integration of hybrid power (wind-photovoltaic-diesel-battery) and seawater reverse osmosis systems for small-scale desalination applications. Desalination 435:210-220

29. Grossmann L, Ebert S, Hinrichs J, Weiss J (2018) Effect of precipitation, lyophilization, and organic solvent extraction on preparation of protein-rich powders from the microalgae Chlorella protothecoides. Algal Res 29:266-276
30. Gu H, Duits MH, Mugele F (2011) Droplets formation and merging in two-phase flow microfluidics. Int J Mol Sci 12(4):2572-2597

31. Gumuscu B, Bomer JG, De Boer HL, Van Den Berg A, Eijkel JC (2017) Exploiting biased reptation for continuous flow preparative DNA fractionation in a versatile microfluidic platform. Microsyst Nanoeng 3:17001

32. Habaki H, Yoshimura Y, Egashira R (2018) Separation of aromatic components from light cycle oil by solvent extraction. Sep Sci Technol 54:1159-1166

33. Hanson C (ed) (2013) Recent advances in liquid-liquid extraction. Elsevier, Amsterdam

34. Harrison CJ, Le Gouellec YA, Cheng RC, Childress AE (2007) Bench-scale testing of nanofiltration for seawater desalination. J Environ Eng 133(11):1004-1014

35. Heggo D, Ookawara S (2017) Multiphase photocatalytic microreactors. Chem Eng Sci 169:67-77

36. Hu R, Feng X, Chen P, Fu M, Chen H, Guo L, Liu BF (2011) Rapid highly efficient extraction and purification of membrane proteins using a microfluidic continuous-flow based aqueous twophase system. J Chromatogr A 1218(1):171-177

37. Huang Y, Meng T, Guo T, Li W, Yan W, Li X, Wang S, Tong Z (2014) Aqueous two-phase extraction for bovine serum albumin (BSA) with co-laminar flow in a simple coaxial capillary microfluidic device. Microfluid Nanofluid 16(3):483-491

38. Jiang F, Pei J, Yin S, Zhang L, Peng J, Ju S, Miller JD, Wang $X$ (2018) Solvent extraction and stripping of copper in a YY type microchannel reactor. Miner Eng 127:296-304

39. Jiang F, Yin S, Zhang L, Peng J, Ju S, Miller JD, Wang X (2018) Solvent extraction of $\mathrm{Cu}$ (II) from sulfate solutions containing $\mathrm{Zn}$ (II) and Fe(III) using an interdigital micromixer. Hydrometallurgy 177:116-122

40. Jiang S, Li Y, Ladewig BP (2017) A review of reverse osmosis membrane fouling and control strategies. Sci Total Environ 595:567-583

41. Jiang Y, Wang H, Li S, Wen W (2014) Applications of micro/ nanoparticles in microfluidic sensors: a review. Sensors 14(4):6952-6964

42. Kamat V, Pandey S, Paknikar K, Bodas D (2018) A facile onestep method for cell lysis and DNA extraction of waterborne pathogens using a microchip. Biosens Bioelectron 99:62-69

43. Kashid MN, Gupta A, Renken A, Kiwi-Minsker L (2010) Numbering-up and mass transfer studies of liquid-liquid two-phase microstructured reactors. Chem Eng J 158(2):233-240

44. Kashid MN, Harshe YM, Agar DW (2007) Liquid - liquid slug flow in a capillary: an alternative to suspended drop or film contactors. Ind Eng Chem Res 46(25):8420-8430

45. Khawaji AD, Kutubkhanah IK, Wie JM (2008) Advances in seawater desalination technologies. Desalination 221(1-3):47-69

46. Kralj JG, Sahoo HR, Jensen KF (2007) Integrated continuous microfluidic liquid-liquid extraction. Lab Chip 7(2):256-263

47. Kurniawan YS, Sathuluri RR, Iwasaki W, Morisada S, Kawakita $\mathrm{H}$, Ohto K, Miyazaki M (2018) Microfluidic reactor for $\mathrm{Pb}(\mathrm{II})$ ion extraction and removal with an amide derivative of calix [4] arene supported by spectroscopic studies. Microchem J 142:377-384

48. Latorre FJG, Báez SOP, Gotor AG (2015) Energy performance of a reverse osmosis desalination plant operating with variable pressure and flow. Desalination 366:146-153

49. Lawal A, Lee W, Besser R, Kientzler D, Achenie L (2010) Microchannel reactor system for catalytic hydrogenation (No. DOE/ G013156-1). Stevens Institute of Technology

50. Leblebici ME, Stefanidis GD, Van Gerven T (2015) Comparison of photocatalytic space-time yields of 12 reactor designs for wastewater treatment. Chem Eng Process 97:106-111 
51. Lei L, Wang N, Zhang XM, Tai Q, Tsai DP, Chan HL (2010) Optofluidic planar reactors for photocatalytic water treatment using solar energy. Biomicrofluidics 4(4):043004

52. Li H, Bashir R (2002) Dielectrophoretic separation and manipulation of live and heat-treated cells of Listeria on microfabricated devices with interdigitated electrodes. Sens Actuators B Chem 86(2-3):215-221

53. Li FT, Liu RH, Wen JH, Zhao DS, Sun ZM, Liu Y (2009) Desulfurization of dibenzothiophene by chemical oxidation and solvent extraction with $\mathrm{Me} 3 \mathrm{NCH} 2 \mathrm{C} 6 \mathrm{H} 5 \mathrm{Cl} \cdot 2 \mathrm{ZnCl} 2$ ionic liquid. Green Chem 11(6):883-888

54. Liang N, Huang P, Hou X, Li Z, Tao L, Zhao L (2016) Solid-phase extraction in combination with dispersive liquid-liquid microextraction and ultra-high performance liquid chromatographytandem mass spectrometry analysis: the ultra-trace determination of 10 antibiotics in water samples. Anal Bioanal Chem 408(6):1701-1713

55. Luo JH, Li J, Guo L, Zhu XH, Dai S, Li X (2017) Removal of chromium(III) from aqueous waste solution by liquid-liquid extraction in a circular microchannel. Water Sci Technol 76(9):2313-2320

56. Mafi M, Dehghani MR, Mokhtarani B (2016) Novel liquid-liquid equilibrium data for six ternary systems containing IL, hydrocarbon and thiophene at $25^{\circ} \mathrm{C}$. Fluid Phase Equilib 412:21-28

57. Majumder M, Chopra N, Andrews R, Hinds BJ (2005) Nanoscale hydrodynamics: enhanced flow in carbon nanotubes. Nature 438(7064):44

58. Malaeb L, Ayoub GM (2011) Reverse osmosis technology for water treatment: state of the art review. Desalination 267(1):1-8

59. Marsousi S, Karimi-Sabet J, Moosavian MA, Amini Y (2019) Liquid-liquid extraction of calcium using ionic liquids in spiral microfluidics. Chem Eng J 356:492-505

60. Maruyama T, Uchida Jl, Ohkawa T, Futami T, Katayama K, Nishizawa Kl, Sotowa Kl, Kubota F, Kamiya N, Goto M (2003) Enzymatic degradation of p-chlorophenol in a two-phase flow microchannel system. Lab Chip 3(4):308-312

61. Mary P, Studer V, Tabeling P (2008) Microfluidic droplet-based liquid-liquid extraction. Anal Chem 80(8):2680-2687

62. Meng Z, Zhang X, Qin J (2013) A high efficiency microfluidicbased photocatalytic microreactor using electrospun nanofibrous $\mathrm{TiO}_{2}$ as a photocatalyst. Nanoscale 5(11):4687-4690

63. Minagawa T, Tokeshi M, Kitamori T (2001) Integration of a wet analysis system on a glass chip: determination of $\mathrm{Co}$ (II) as 2-nitroso-1-naphthol chelates by solvent extraction and thermal lens microscopy. Lab Chip 1(1):72-75

64. Miura T, Yokokawa R (2016) Tissue culture on a chip: developmental biology applications of self-organized capillary networks in microfluidic devices. Dev Growth Differ 58(6):505-515

65. Miyaguchi $\mathrm{H}$, Tokeshi M, Kikutani Y, Hibara A, Inoue H, Kitamori T (2006) Microchip-based liquid-liquid extraction for gas-chromatography analysis of amphetamine-type stimulants in urine. J Chromatogr A 1129(1):105-110

66. Mohammad AW, Teow YH, Ang WL, Chung YT, Oatley-Radcliffe DL, Hilal N (2015) Nanofiltration membranes review: recent advances and future prospects. Desalination 356:226-254

67. Mu X, Liang Q, Hu P, Ren K, Wang Y, Luo G (2010) Selectively modified microfluidic chip for solvent extraction of Radix Salvia Miltiorrhiza using three-phase laminar flow to provide double liquid-liquid interface area. Microfluid Nanofluid 9(2-3):365-373

68. Nam J, Lim H, Kim D, Shin S (2011) Separation of platelets from whole blood using standing surface acoustic waves in a microchannel. Lab Chip 11(19):3361-3364
69. Nandagopal MG, Antony R, Selvaraju N (2016) Comparative study of liquid-liquid extraction in miniaturized channels over other conventional extraction methods. Microsyst Technol 22(2):349-356

70. Nichols KP, Pompano RR, Li L, Gelis AV, Ismagilov RF (2011) Toward mechanistic understanding of nuclear reprocessing chemistries by quantifying lanthanide solvent extraction kinetics via microfluidics with constant interfacial area and rapid mixing. J Am Chem Soc 133(39):15721-15729

71. Novak U, Pohar A, Plazl I, Žnidaršič-Plazl P (2012) lonic liquidbased aqueous two-phase extraction within a microchannel system. Sep Purif Technol 97:172-178

72. Novak U, Lakner M, Plazl I, Žnidaršič-Plazl P (2015) Experimental studies and modeling of a-amylase aqueous two-phase extraction within a microfluidic device. Microfluid Nanofluid 19(1):75-83

73. Oelgemoeller $M(2012)$ Highlights of photochemical reactions in microflow reactors. Chem Eng Technol 35(7):1144-1152

74. Pahlavanzadeh $\mathrm{H}$, Khayati G, Ghaemi N, Vasheghani-Farahani $\mathrm{E}$ (2012) Liquid-liquid extraction of 2,3-butanediol from fermentation broth. Iran J Chem Chem Eng (IJCCE) 31(2):59-63

75. Pan X, Jiang L, Liu K, Lin B, Qin J (2010) A microfluidic device integrated with multichamber polymerase chain reaction and multichannel separation for genetic analysis. Anal Chim Acta 674(1):110-115

76. Pérez JF, Llanos J, Sáez C, López C, Cañizares P, Rodrigo MA (2017) A microfluidic flow-through electrochemical reactor for wastewater treatment: a proof-of-concept. Electrochem Commun 82:85-88

77. Pérez JF, Llanos J, Sáez C, López C, Cañizares P, Rodrigo MA (2018) Development of an innovative approach for low-impact wastewater treatment: a microfluidic flow-through electrochemical reactor. Chem Eng J 351:766-772

78. Petrus JCC, Tessaro IC (2016) Processo de Separação com Membranas. In: Tadini CC (org.) Operações Unitárias na Indústria de Alimentos, v. 2, LTC, Rio de Janeiro, Brazil

79. Prudich $M E$, Chen $H$, Gu HT, Gupta RB, Johnston KP, Lutz $H$, Ma G, Su Z (2018) Alternative separation processes. In: Perry's Chemical Engineer's handbook, 8 edn. McGraw Hill, New York

80. Ramos-Payan M, Maspoch S, Llobera A (2016) An effective microfluidic based liquid-phase microextraction device ( $\mu$ LPME) for extraction of non-steroidal anti-inflammatory drugs from biological and environmental samples. Anal Chim Acta 946:56-63

81. Razmara RS, Daneshfar A, Sahrai R (2011) Determination of methylene blue and sunset yellow in wastewater and food samples using salting-out assisted liquid-liquid extraction. J Ind Eng Chem 17(3):533-536

82. Rodríguez-Villarreal Al, Arundell M, Carmona M, Samitier J (2010) High flow rate microfluidic device for blood plasma separation using a range of temperatures. Lab Chip 10(2):211-219

83. Schweitzer PA (1988) Handbook of separation techniques for chemical engineers. McGraw-Hill, New York, pp 1-386

84. Scialdone O, Corrado E, Galia A, Sirés I (2014) Electrochemical processes in macro and microfluidic cells for the abatement of chloroacetic acid from water. Electrochim Acta 132:15-24

85. Scialdone O, Galia A, Sabatino S (2013) Electro-generation of $\mathrm{H}_{2} \mathrm{O}_{2}$ and abatement of organic pollutant in water by an electro-Fenton process in a microfluidic reactor. Electrochem Commun 26:45-47

86. Scialdone O, Galia A, Sabatino S (2014) Abatement of Acid Orange 7 in macro and micro reactors. Effect of the electrocatalytic route. Appl Catal B 148:473-483 
87. Scialdone O, Guarisco C, Galia A (2011) Oxidation of organics in water in microfluidic electrochemical reactors: theoretical model and experiments. Electrochim Acta 58:463-473

88. Seyfi S, Abdi M (2009) Extraction of titanium(IV) from acidic media by tri-n-butyl phosphate in kerosene. Miner Eng 22(2): $116-118$

89. Sia SK, Whitesides GM (2003) Microfluidic devices fabricated in poly(dimethylsiloxane) for biological studies. Electrophoresis 24(21):3563-3576

90. Singh KK, Renjith AU, Shenoy KT (2015) Liquid-liquid extraction in microchannels and conventional stage-wise extractors: a comparative study. Chem Eng Process 98:95-105

91. Soares RR, Azevedo AM, Fernandes P, Chu V, Conde JP, AiresBarros MR (2017) A simple method for point-of-need extraction, concentration and rapid multi-mycotoxin immunodetection in feeds using aqueous two-phase systems. J Chromatogr A 1511:15-24

92. Song Y, Su B, Gao X, Gao C (2012) The performance of polyamide nanofiltration membrane for long-term operation in an integrated membrane seawater pretreatment system. Desalination 296:30-36

93. SooHoo JR, Walker GM (2009) Microfluidic aqueous two phase system for leukocyte concentration from whole blood. Biomed Microdevice 11(2):323-329

94. Sorribas S, Gorgojo P, Téllez C, Coronas J, Livingston AG (2013) High flux thin film nanocomposite membranes based on metal-organic frameworks for organic solvent nanofiltration. J Am Chem Soc 135(40):15201-15208

95. Sun Y, Haglund TA, Rogers AJ, Ghanim AF, Sethu P (2018) Microfluidics technologies for blood-based cancer liquid biopsies. Anal Chim Acta 1012:10-29

96. Tabeling P (2005) Introduction to microfluidics. Oxford University Press, Oxford

97. Tagawa T, Aljbour S, Matouq M, Yamada H (2007) Micro-channel reactor with guideline structure for organic-aqueous binary system. Chem Eng Sci 62(18-20):5123-5126

98. Tripathi S, Prabhakar A, Kumar N, Singh SG, Agrawal A (2013) Blood plasma separation in elevated dimension T-shaped microchannel. Biomed Microdevice 15(3):415-425

99. Tsaoulidis D, Dore V, Angeli P, Plechkova NV, Seddon KR (2013) Flow patterns and pressure drop of ionic liquid-water twophase flows in microchannels. Int J Multiph Flow 54:1-10
100. Vaghi V, Potrich C, Pasquardini L, Lunelli L, Vanzetti L, Ebranati E, Lai A, Zehender G, Mombello D, Cocuzza M, Pirri CF, Pederzolli $C$ (2016) On-chip purification and detection of hepatitis $C$ virus RNA from human plasma. Biophys Chem 208:54-61

101. Van Gerven T, Mul G, Moulijn J, Stankiewicz A (2007) A review of intensification of photocatalytic processes. Chem Eng Process 46(9):781-789

102. Voloshin $Y$, Halder R, Lawal A (2007) Kinetics of hydrogen peroxide synthesis by direct combination of $\mathrm{H}_{2}$ and $\mathrm{O}_{2}$ in a microreactor. Catal Today 125(1-2):40-47

103. Wang N, Zhang X, Chen B, Song W, Chan NY, Chan HL (2012) Microfluidic photoelectrocatalytic reactors for water purification with an integrated visible-light source. Lab Chip 12(20):3983-3990

104. Wang N, Zhang X, Wang Y, Yu W, Chan HL (2014) Microfluidic reactors for photocatalytic water purification. Lab Chip 14(6):1074-1082

105. Wang K, Luo G (2017) Microflow extraction: a review of recent development. Chem Eng Sci 169:18-33

106. Wei L, Guo S, Yan G, Chen C, Jiang X (2010) Electrochemical pretreatment of heavy oil refinery wastewater using a three-dimensional electrode reactor. Electrochim Acta 55(28):8615-8620

107. Whitesides GM (2006) The origins and the future of microfluidics. Nature 442(7101):368

108. Xie T, Chen M, Xu C, Chen J (2019) High-throughput extraction and separation of $\mathrm{Ce}(\mathrm{III})$ and $\operatorname{Pr}(\mathrm{III})$ using a chaotic advection microextractor. Chem Eng J 356:382-392

109. Zhang C, Jiang Y, Li Y, Hu Z, Zhou L, Zhou M (2013) Threedimensional electrochemical process for wastewater treatment: a general review. Chem Eng J 228:455-467

110. Zhao M, Cao S, Duan W (2014) Effects of some parameters on mass-transfer efficiency of a $\$ 20 \mathrm{~mm}$ annular centrifugal contactor for nuclear solvent extraction processes. Prog Nucl Energy 74:154-159

111. Zhao Y, Chen G, Yuan Q (2007) Liquid-liquid two-phase mass transfer in the T-junction microchannels. AIChE J 53(12):3042-3053

Publisher's Note Springer Nature remains neutral with regard to jurisdictional claims in published maps and institutional affiliations. 